\title{
Simulating the Optimization of Carbon Fiber Reinforced Polymer as a Wrapping Structure on Piping System Using SolidWorks
}

\author{
Shaktivell M. Letchumanan • Ahmad Mubarak Tajul Arifin • Ishkrizat Taib • \\ Mohammad Zulafif Rahim • Nor Adrian Nor Salim
}

Submitted: 30 June 2021 / in revised form: 21 September 2021/Accepted: 18 October 2021/Published online: 19 November 2021

(C) ASM International 2021

\begin{abstract}
Carbon Fiber Reinforced Polymer (CFRP) was designed, simulated, and evaluated as a wrapping material on defected pipe using computational approach. This composite material was considered as a unique wrapping material as it may have the combined characteristics of the constituents or have substantially different properties than the individual constituents. Specifically, this research evaluates the capability of CFRP as a wrapper through SolidWorks Simulation using the static analysis, computational fluid dynamics analysis, and data analysis. This approach gives a preliminary consideration and justification on choosing the optimized lamination orientation of CFRP in real cases based on the simulated data. Various orientations were simulated and analyzed throughout this research. Based on all the simulation analysis, the CFRP wrapper with quasi-isotropic lamination with the 8 plies $\left(45^{\circ} / 90^{\circ} / 0^{\circ} / 45^{\circ}\right)_{\mathrm{s}}$ orientation was seen most effective in reducing the stress and possess highest minimum safety factor at the fully defected region $(100 \times 100 \times 7.11 \mathrm{~mm}$ thru) after the repair. Eventually, this optimized CFRP lamination orientation, proved that it was able to withstand pressures ranging between 0.86 to $19.6 \mathrm{MPa}$ with a layer thickness in between 0.16 up to $3.76 \mathrm{~mm}$. Based on the static analysis, this optimized laminated orientation of
\end{abstract}

This article is an invited paper selected from presentations at the 5th Symposium on Damage Mechanism in Materials and Structures (SDMMS 20-21), held March 8-9, 2021 in Penang, Malaysia and has been expanded from the original presentation.

S. M. Letchumanan · A. M. Tajul Arifin $(\varangle) \cdot$ I. Taib ·

M. Z. Rahim · N. A. Nor Salim

Faculty of Mechanical Manufacturing and Engineering,

Universiti Tun Hussein Onn Malaysia, Parit Raja, Batu Pahat,

Johor 86400, Malaysia

e-mail:mubarak@uthm.edu.my
CFRP indeed showed that it was able to reduce the stress on an average of $94.10 \%$ after the repair was done. Relatively, CFRP was $0.2 \%$ higher in reducing the maximum stress at the defected region at the pipe, than the Glass Fiber Reinforced Polymer with the same orientation. Additionally, the flow simulation analysis in SolidWorks showed that fluid flow was undisrupted after the repair was done, and the wrapped region was resistant to any fluid leakages.

Keywords Carbon fiber reinforced polymer (CFRP) . Static analysis - Lamination orientation .

Wrapping structure $\cdot$ Computational fluid dynamics (CFD)

\section{Introduction}

Pipeline systems are regarded as critical infrastructure among current infrastructural facilities, particularly in the oil and gas sectors and other associated businesses [1]. Due to the risk exposure is so significant in these industries, safety is given top attention. Pipe failure is always reduced by a combination of design, material, and operating methods. Piping system failure is also caused by natural occurrences and exposure to key components. These exposures eventually will cause the pipe material to experience volumetric loss and in long-term results in leakages $[2,3]$. Figure 1a basically shows the volumetric loss process in the steel pipe while Fig. 1b shows the uneven depth profile due to corrosion that extends in both longitudinal and circular directions in an irregular pattern. As corrosion is part of the volumetric loss, pipe repairing method is substantially important in maintaining the structural integrity of the pipe. 
Fig. 1 (a) Volumetric loss due to corrosion in pipeline surface, (b) the irregular depth, width, and length due to corrosion on a defected pipe [55-57]

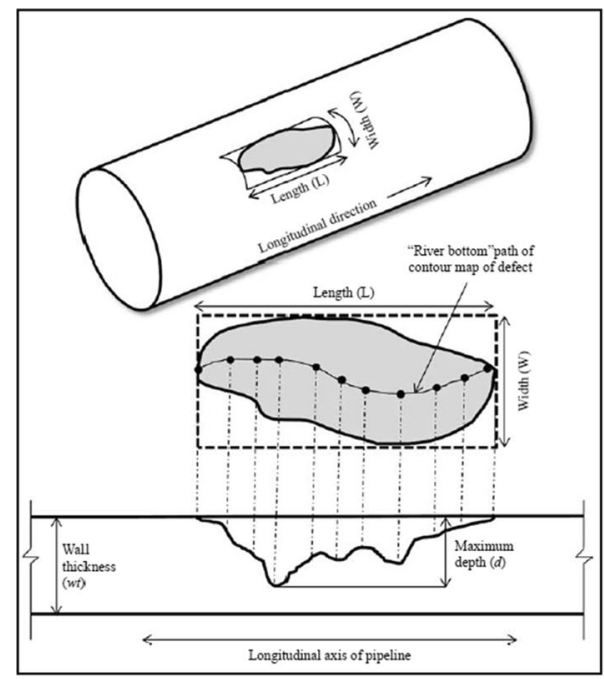

(a)

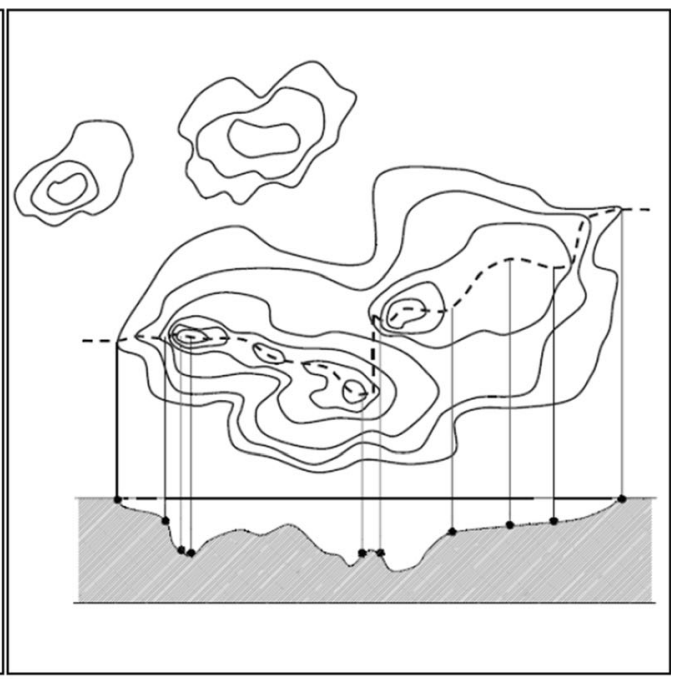

(b)
Furthermore, severe defects such as gouges on welds, kinked dents, and smooth dents must be addressed immediately too [4]. Various pipe leakage detection technologies, including external, visual, and internal scopes, can be employed to consider a proper repairing method. Since pipelines are highly long-serving and vital infrastructure, it is critical to preserve this structure from all types of flaws. Therefore, to preserve the pipeline structure's durability is most likely maintained by the wrapping structure that covers the pipe. Wrapping the whole leaky pipeline segment is the best option for preventing existing defects that may lead to severe leakages [5]. This is to ensure that product flow is undisrupted in the pipeline system.

In general, composite material was preferred over other materials as the wrapping material since it is recognized for its ability to change its characterization dependent on the requirements. This composite material wrapping approach is gaining popularity and acceptance across the world, since it follows international engineering standards and provides a designed, proven, and long-lasting solution to both metallic and non-metallic repair work [6, 7]. This composite material has a unique property depending on how the components are mixed, the final composite material may have the combined qualities of the constituents or considerably different properties than the individual elements [8]. In general perspectives, the CFRP was considered as the one of the unique materials in the composite category where it possesses low density, high tensile strength, low thermal expansion, high rigidity, high stiffness, and corrosion resistance compared to other fiber reinforced polymer materials [9, 10]. Carbon fibers are incredibly thin filaments with a diameter of $5-10 \mu \mathrm{m}$ in size that are hardly visible to the naked eye [11]. Having such a fine element didn't restrict those fibers to exhibits better properties than other materials. Though the CFRP is theoretically known as an advanced and effective material, but it is relatively expensive too. To consider CFRP as a wrapping material for the defected pipe needs, proper data are needed to prove its effectiveness for justification purposes.

Moreover, this research was very concerned to counter the two potential failure modes for composite repair systems that do exist till this date. The first mode of failure occurs when the composite wrap is overloaded. In rare cases, the substrate will break before the composite wrap, resulting in increased load transfer from the substrate and composite burst failure. The second failure mode involves delamination of the composite laminate from the substrate due to a decrease of bonding strength [5]. As a result, to ensure that the composite laminate is not overloaded and stays attached to the substrate, this research is optimistic in getting the right orientation and the right thickness of CFRP that could withstand the minimum and maximum pressure by maintaining the steady fluid flow solely through SolidWorks simulation with proper parameter setup [12]. This makes the research to be distinctive because during simulation itself, it is possible to get to know whether the applied wrapper is suitable and optimized, could withstand the fluid pressure, and it doesn't create any overload or excessive stress on the repaired pipe. As most of the mechanical engineers around the globe are more familiar and convenient in using this software, this research is optimistic in providing all the related analysis including the CFD analysis entirely with SolidWorks [13]. Eventually, it may make engineers to consider solely to use this CAD software particularly whenever they are coming across cases that involves composite material and fluid 
flow rather than working with multiple software to obtain simulation data.

Taking the failure mode of the composites and the utilization of composite only on non-leaking pipe structure into concern, this research will provide a guideline on simulating the performance of the CFRP as the wrapping material with various lamination orientation on the pipe with SolidWorks. Simulated visuals and data will eventually provide the suitable and effective wrapping orientation, thickness and number of layers to be considered to wrap the defected region subject to the parameters that referred from real situation. This approach will reduce the time and cost on deciding and evaluating the right wrapping structure for real cases, and it could also provide the potential failure visuals on the pipe before actual wrapping is done.

\section{Materials}

\section{CFRP as a Wrapping Material}

Advanced composite materials have been utilized to repair transmission pipelines for more than 20 years. Particulate composites, flake composites, fiber reinforced composites, and laminated composites are the four kinds of composites in general [14, 15]. The most frequent type of component combination is the fiber-reinforced composites. Pipeline repair methods employ a wide range of composite materials. Glass and carbon fiber reinforcement are mostly used in a thermoset polymer matrix (e.g., polyester, polyurethane, and epoxy) [5]. The major load-carrying element in such composites is the fiber, which is typically strong and stiff.

In common practice, there are 6 types of pipes repairing method that are in use. Grinding out and recoating, steel reinforcement sleeve repair (type A sleeve), steel pressurecontaining sleeve repair (type B sleeve), composite wrap repair, hot tap section, and pipe replacement were the existing methods. Although composite materials are under advanced development for more than 20 years but the composites in pipe repairing system are not fully utilized. ASME B31.8 currently limits the use of composites to only corrosion repair of non-leaking pipes unless the repair is proven through reliable testing and analysis [5, 16]. Therefore, the outcome from this research will eventually contribute for the utilization of composite wrapper for the fully defected (wall loss) or leaking pipe structure via simulation. Composite material is said to be a material that is particularly easy to utilize by hand lay-up techniques since it has a lot of flexibility in terms of lay-up orientations. In composite wrap repair, hand lay-up technique and clock spring method are in common practice as illustrated in Fig. 2. These techniques, creates the possibilities to do any alteration on the orientation in real situation.

The critical process to alter the lamination orientation of the composites is done to attain the suitable properties that could withstand various pressure from the defected pipe region either by unidirectional quasi-isotropic or crosspiled quasi-isotropic lamination as illustrated in Fig. 3. Unidirectional quasi-isotropic indicates that all the reinforcements are aligned in same directions across all the planes while the cross-piled quasi-isotropic lamination indicates that reinforcement orientations differ across planes [17]. Since CFRP is part of the fiber-reinforced composite category, the sort of pattern that may be created should be determined at first. As rapid development was done across decades, lately the mechanical properties of the CFRP were very much improved compared to other type of material especially materials like steel. In general, CFRP could have either isotropic or orthotropic properties subject to the fibers' alignment [18]. Since there were not much mechanical properties differences in between the isotropic and orthotropic CFRP material, therefore this research takes the orthotropic properties into concern as lamination orientations plays the major role in this research and considering the accessibility of CFRP orthotropic property data that could give better analysis data based on axis [19]. In this case, geometrically the lamination of CFRP is quasi-isotropic, and it will have orthotropic properties where it will possess the same strength and stiffness in all direction but only in-plane and will differ planes to planes [17]. This must be explained in detail because this research is concerned on different lamination orientation of CFRP as a wrapper.

Polymer resins in the CFRP are the key reinforcement that gives the mechanical strength to the whole composite structure. Therefore, polymer resin for CFRP is categorized into two, where one is known as the thermoplastic resin, and the other one is the thermosetting resin. The usage of this resin simultaneously changes the mechanical strength of the composite structure relatively with different mechanical-thermal responses [20, 21]. Although both type resins responses accordingly with thermal and mechanical exposure but both the resins differ accordingly with molecular structures and properties. Thermoplastic resin are polymers that linked with intermolecular interactions that forms branched or linear molecular structure. This molecular structure allows the thermoplastics remelt able and tractable. On the other hand, thermosetting resins are polymers that were bonded with chemical bonding, forming highly cross-linked molecular structure. This restricts the thermosets from being remelting or intractable upon heat and pressure after curing [22, 23]. For visual aid, the following Fig. 4 illustrates the molecular structure of 

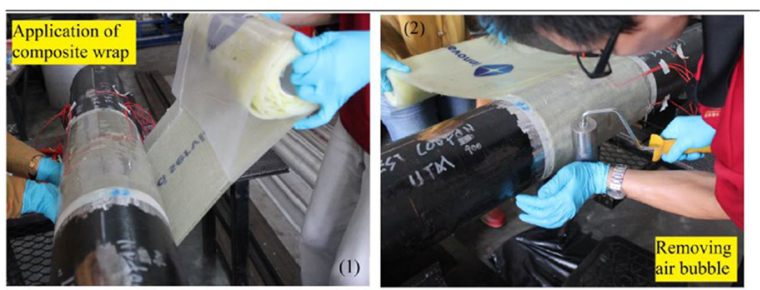

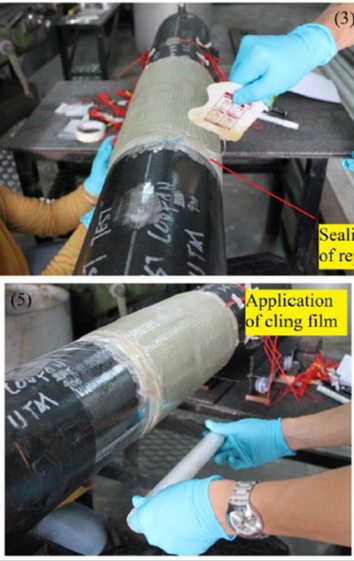

(a)

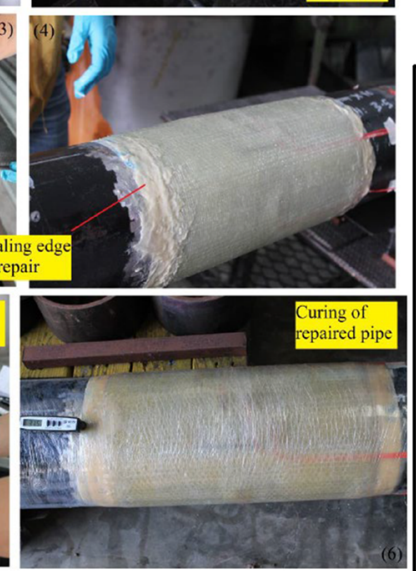

(b)

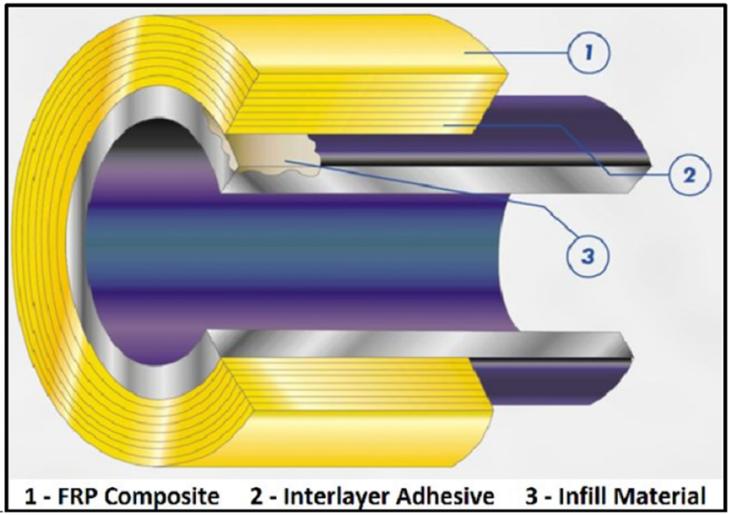

Fig. 2 (a) Composite hand lay-up technique, (b) clock Spring® FRP composite repair system [32, 58]

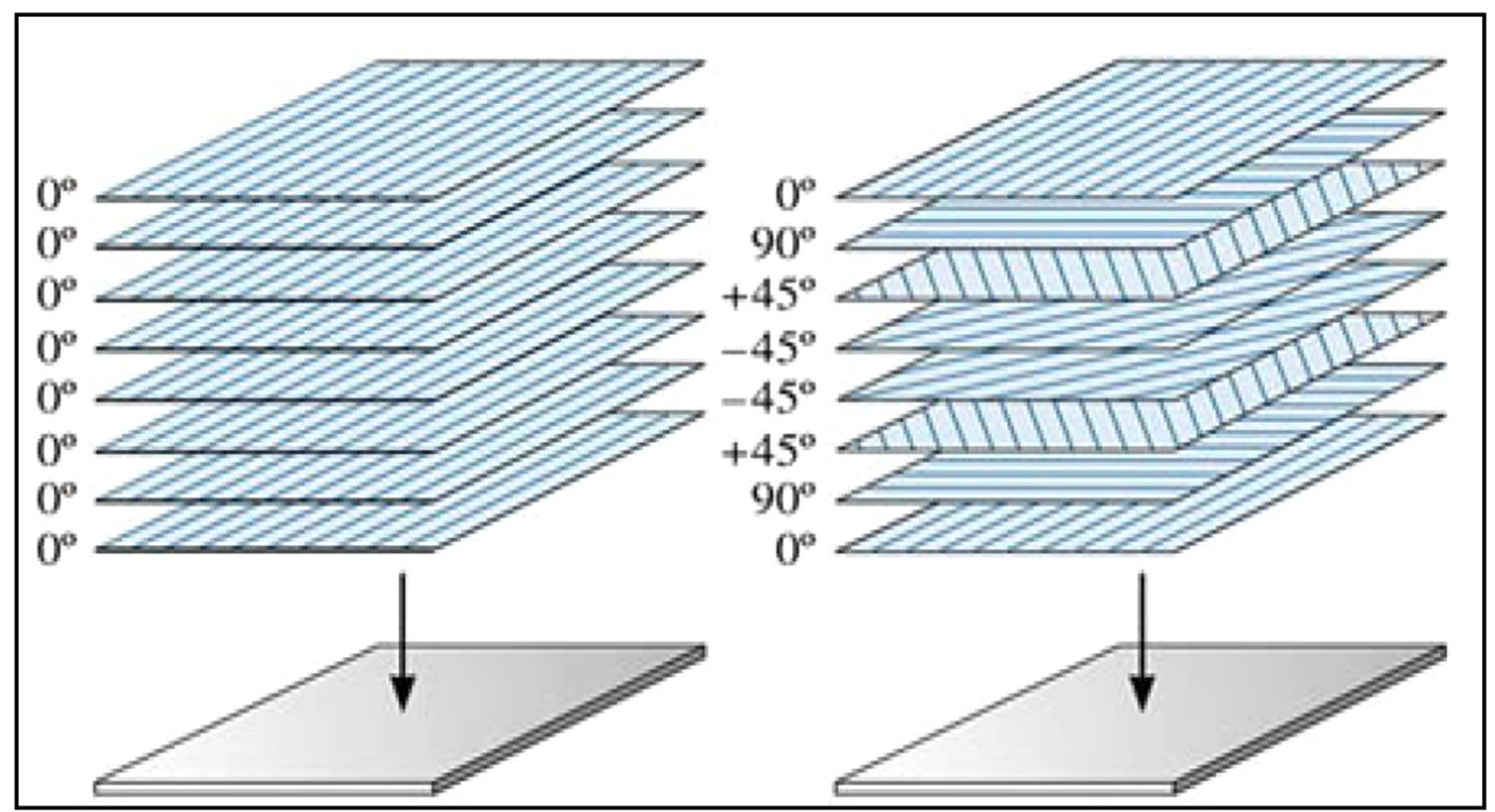

(a)

(b)

Fig. 3 (a) Unidirectional quasi-isotropic, (b) cross-piled quasi-isotropic lamination [17]

polymer resin for better understanding on thermosets and thermoplastics.

As mentioned earlier, the polymer resin plays a key role in deciding the mechanical properties of the CFRP. It is very necessary to get to know the mechanical properties of both the polymer resins. By referring to Table 1 below, it can be seen that the thermosetting resin is the right choice for this research upon considering its application. Since heat and pressure plays a major role in the pipe defect wrapping the thermoplastic is not suitable to be used as it could remelt. On the other hand, the thermosetting is advisable to be used as it could withstand the pressure and thermal stress when these properties are increased. Among, the thermosetting resins, Epoxy is very much suitable to be 
Fig. 4 (a) Molecular structures of thermoplastic resins and (b) Thermosetting resins [20]

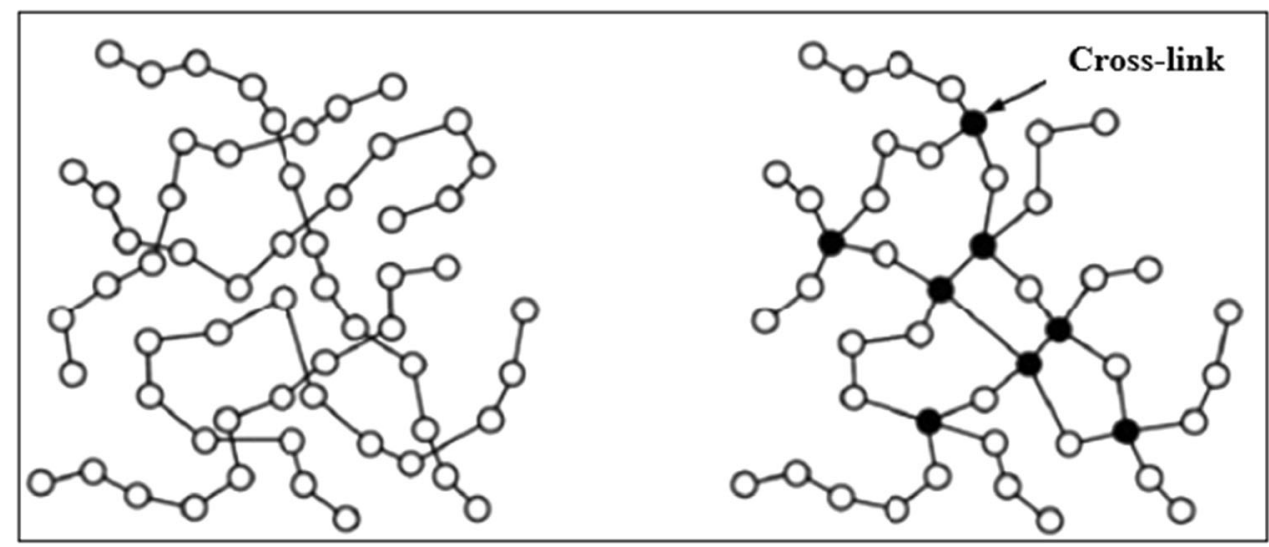

(a) (b)
Table 1 Mechanical properties of commonly used polymer resins $[59,60]$

\begin{tabular}{llccc}
\hline \multirow{2}{*}{ Type } & \multicolumn{1}{c}{ Name } & Density & $\begin{array}{c}\text { Tensile } \\
\text { strength }\end{array}$ & $\begin{array}{c}\text { Elastic } \\
\text { modulus }\end{array}$ \\
\hline Thermoplastic & Polyethersulfone & 1370 & 0.084 & 2.4 \\
& Polyetherether ketone & 1310 & 0.070 & 3.8 \\
& Polyetherimide & 1270 & 0.105 & 3.0 \\
Thermosetting & Orthophthalic polyester & 1350 & 0.070 & 3.2 \\
& Vinylester & 1250 & 0.075 & 3.3 \\
& Epoxy & 1250 & 0.115 & 3.0 \\
\hline
\end{tabular}

used as resin. This is because by comparing both Orth phthalic polyester and Vinyl ester, the epoxy has lower density and tensile strength even though it has lower elastic modulus [20, 21]. It is very much concerned that the prior modification should be used as the synergistic fashion with a polymer resin to realize their superior mechanical properties [11].

Despite the fact that the GFRP has been in common use as a wrapping material in pipeline but CFRP appears to possess as a better wrapping material. It is due to its better mechanical properties which is having higher tensile strength, elastic modulus, less dense, lower thermal expansion, higher safety factor in stresses with higher probability of avoiding the failure, higher natural frequencies of the mode shapes with probability to avoid the resonance [24, 25]. Considering the mechanical properties of CFRP, the right orientation lamination of CFRP as the wrapping material on defected pipe that could withstand various range of fluid pressures with optimum thickness was simulated using SolidWorks and analyzed through static analysis, CFD analysis and data analysis which gave convincible data for the preliminary justification that could give the consideration of that particular wrapping structure in real cases.

\section{API 5L Grade B Pipe Specifications}

Selecting the right pipe specifications is a very important step for the desired application. It is very necessary to assign the right material for the right fluid transportation system. In this scenario, codes and standards play a major role in defining the right pipe specifications. As pipe is considered a very critical and important structure in transporting any kind of product from one location to another location for a far distance, the limits of the pipes too need to be identified. As diameter and thickness play a major role in determining the pipe sustainability against the fluid flow, it is very important to consider the technical terminologies that are involved in pipe selection. Nominal Pie Size (NPS) is basically required to determine the name of the pipe based on ASTM/ASME Standards. As NPS is normally associated with Internal Diameter (ID) ranging from $1 / 8^{\prime \prime}$ to $12^{\prime \prime}$, sizes above $14^{\prime \prime}$ are considered equals to Outside Diameter (OD). OD and ID as the name imply, referred to actual outside and inside diameters. It is known that OD will remain unchanged with pipe sizes irrespective of pipe thickness [26].

On the other hand, wall thickness $(t)$ or better known as pipe schedule $(\mathrm{SCH})$ determines the thickness of the pipe. Pipe schedule is known as a non-dimensional number that determines the thickness of pipe wall and effects the internal diameter of the pipe. It is used to classify pipes for high and low pressure and temperature application. It is known that wall thickness may differ according to pipe schedule for the same NPS. In common, the schedules 40 and 80 are the schedule number used for most of the pipe sizes [27]. When the OD and wall thickness are determined the schedule and NPS could be determined by using the ASME/ANSI B36.10M Schedule Chart. Material selection for the pipe also considered a very important specification as it determines the structural integrity of the pipe too.

Commonly Carbon Steel, Alloy Steel, Stainless Steel, Austenitic Steel, Ferritic Steel, Martensitic Steel, Duplex 
Stainless Steel, Cast or Ductile Iron, Galvanized Pipe, Titanium, Copper, Brass, Copper Nickel Alloys and Plastics are frequently used as pipe material. Among this, carbon steel and stainless steel are the two popular material that are used in piping structure. Moreover, the Grade in steel pipes are the designated divisions to differentiate the different type of pipe sizes based on carbon content and mechanical properties. In general, there are two types of Grades that are involved in determining the pipe quality, the first one is Grade A while the other one is Grade B. Grade A steel pipe possess the less tensile strength and yield strength where these graded pipes are more ductile due to lower carbon content. However, the Grade B steel pipes which could withstand the pressure, structural strength and possess higher tensile strength and yield strength due to higher carbon content [28].

The consideration of fluid services by ASME B31.3 needs to be considered into pipe specification also as it gives a better scope to consider a sustainable pipe specification based on standards. Based on ASME B31.3, the fluid services are categorized into 4 categories where they are known as Category D, Normal, High Pressure, and Category M. As this research focusses on the hydrocarbons or specifically fuel, the ASME B31.3 gives a very clear guidance on categorizing the fluid into Normal Category. As hydrocarbon is considered a process fluid with a maximum allowable pressure based on yield strength which is $165 \mathrm{MPa}$ which is also flammable and has a temperature value between -30 till $120^{\circ} \mathrm{C}$ according to ASME B31.4, this fluid is eligible to be considered as normal fluid service. This specification was further justified based on ASME B31.4 Table 402.3.1 (a). In common, API 5L Grade $\mathrm{B}$ pipe is used for oil and gas transmission. Therefore, this

Table 2 API 5L grade B pipe specification [61, 62]

\begin{tabular}{|c|c|}
\hline Properties & Specification \\
\hline Grade & API 5L Grade B Pipe \\
\hline Manufacturing type & $\begin{array}{l}\text { Seamless, ERW, LSAW, SSAW/ } \\
\text { HSAW }\end{array}$ \\
\hline Outer diameters & $1 / 2 "-60 "$ \\
\hline Thickness & $\begin{array}{l}\text { SCH } 20, \text { SCH } 40, \text { SCH STD, SCH } \\
80 \text { to SCH } 160\end{array}$ \\
\hline Range of length & SRL, DRL, 20FT, 40FT, 5-12 m \\
\hline Production specification & PSL1, PSL2, sour services \\
\hline Ends & Plain, BEVELLED \\
\hline Coatings & $\begin{array}{l}\text { FBE, 3PE/3LPE, black painting, } \\
\text { varnished }\end{array}$ \\
\hline Seamless pipe minimum & 245 \\
\hline \multicolumn{2}{|l|}{ Yield STRENGTH (MPa) } \\
\hline $\begin{array}{l}\text { Seamless pipe tensile strength } \\
\text { (MPa) }\end{array}$ & 415 \\
\hline
\end{tabular}

research will also consider using the same pipe type. The specification of this type of pipe is tabulated in Table 2 .

\section{Computational Analysis on Simulating the CFRP} as Pipeline Wrapping Structure

Once the pipe specifications and CFRP properties were identified the computational approach could be done. As the goal of this study is to simulate the CFRP as the wrapping material on a defective pipe structure with various lamination orientations, theoretical criteria for simulations must be established before moving on to the simulation. SolidWorks is computer-aided design (CAD) software for creating 2D and 3D structures. This is basic but very effective programming software that helps designers and engineers to generate highly detailed components and assemblies, as well as sketches at the production stage. SolidWorks is a fantastic tool for managing several stages of product development [29]. SolidWorks software can perform a variety of analyses and simulations too. This study focuses on running simulations and analyses solely with SOLIDWORKS software to ensure that a basic concept could be formed before going on to an experimental method.

Since the SolidWorks software can do static studies, flow simulations, and failure simulations in general, it is thought that this software will be able to give better visual analysis as well as numerical analysis data for compelling proposals. These three primary pillars can produce preliminary considerations and justifications in choosing the right lamination orientations of CFRP that will serve as a point of reference for experimental approaches in the near future. Though simulations software like ABAQUS and ANSYS do commonly used to study the CFD analysis and composite simulation, but this research is optimistic in modeling the pipe and CFRP, analyze them via simulation using SolidWorks. Upon modeling the pipe structure based on standards and codes, 'Flow Simulation' add-in in SolidWorks was used to measure fluid flows through the model. This approach helps to identify the problematic area in a pipe and could improve the model before manufacturing that part. Flow simulation specifically addresses the fluid flow in a fully closed volume as illustrated in Fig. 5.

The add-in for Flow simulation uses at least one inlet and one outlet, which is exactly what was used in this simulation concept. The lids were designed to seal the pipes to perform a simulation. With the basics of extrusion feature with suitable parameters or boundary conditions, SolidWorks Flow Simulation able to simulate the pipe performance with various fluid properties [30]. Figure 6a are the boundary conditions like the inlet pressure, outer pressure and operating temperature along with fluid 

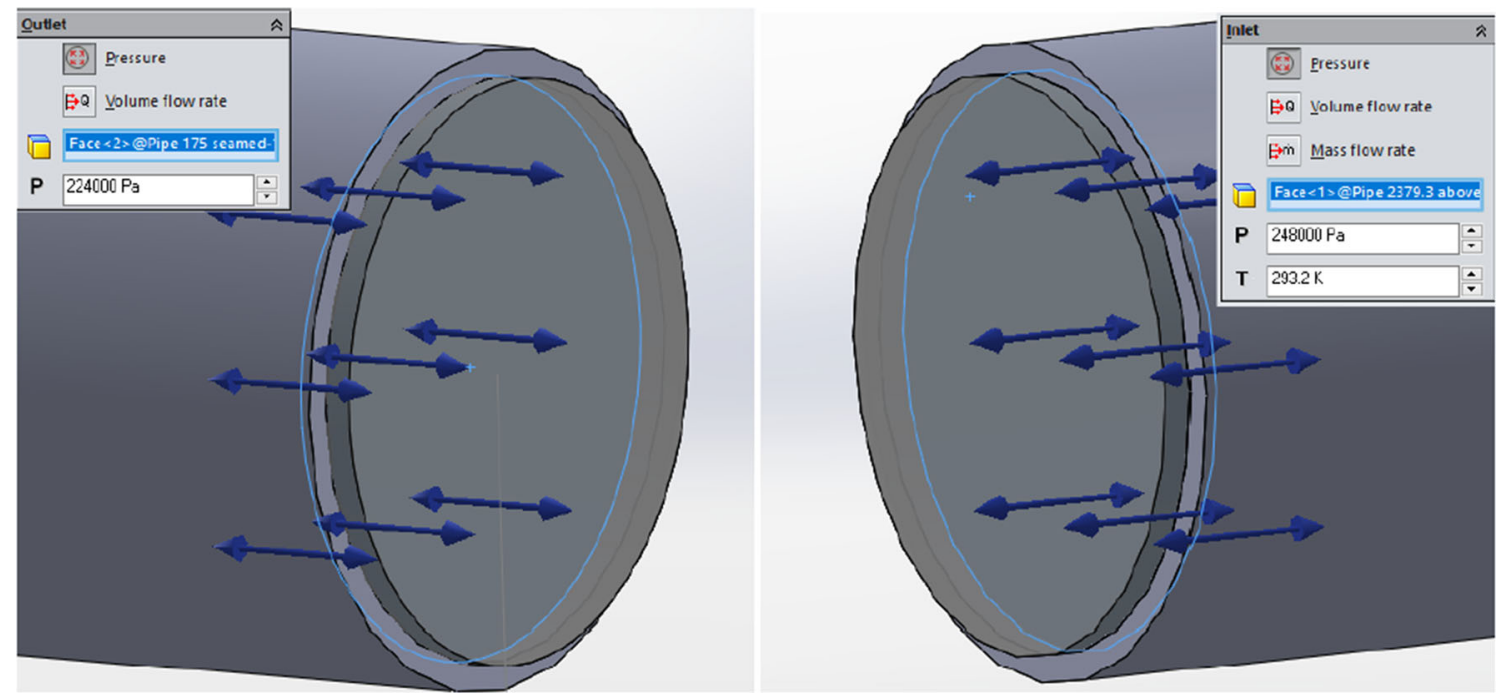

Fig. 5 A flow analysis could be only simulated if the model is enclosed without any leakages [29]

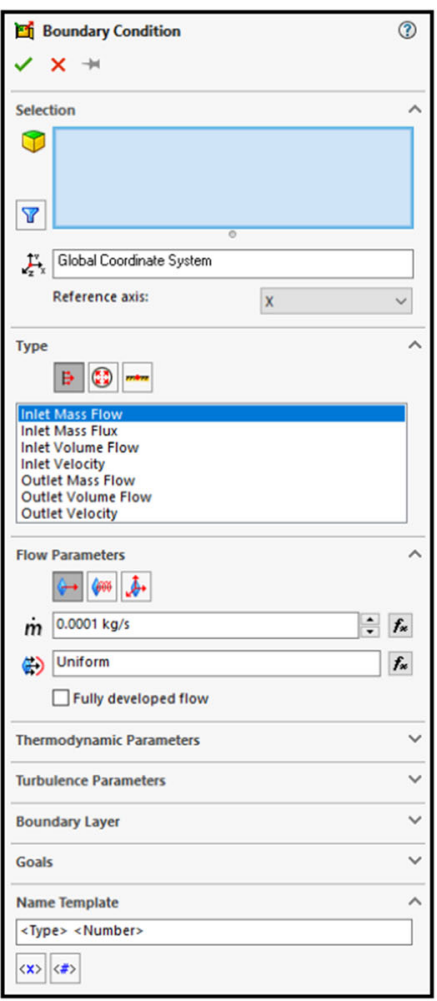

(a)

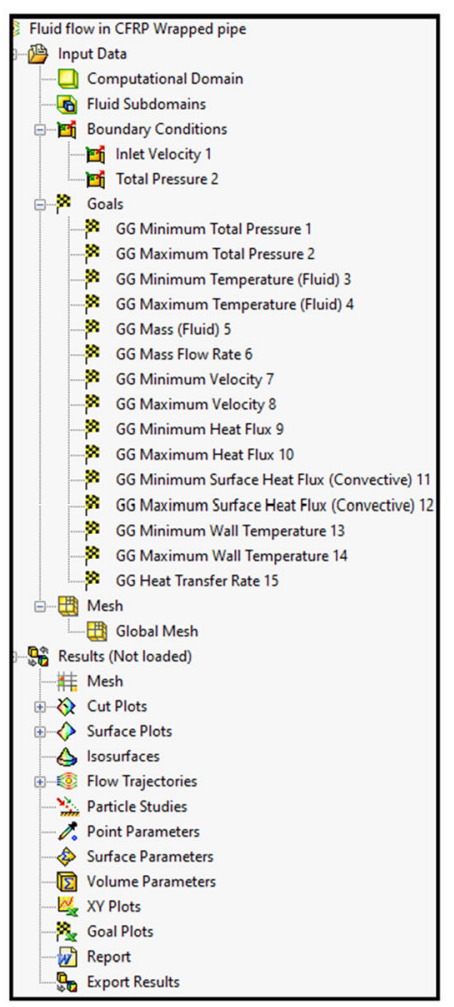

(b)

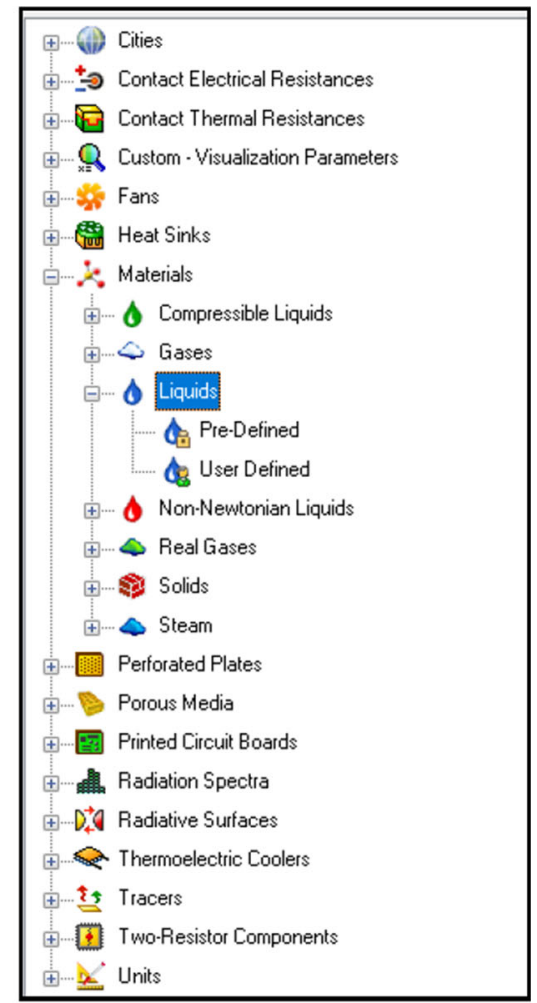

(c)

Fig. 6 (a) Boundary Conditions for inlet substance, (b) goals or results that could be achieved, (c) various inlet substance

velocity that needs to be set to run the flow simulations, while Fig. $6 \mathrm{~b}$ is the various results approach that could be achieved to analyze the data. In Fig. 6c, it could be seen that the SolidWorks Flow Simulation provides various inlet substances from its directory, and it shows that custom substance could be keyed in if the fluid properties is known [31].

\section{Methodology}

Considering the simulation could only be done with proper parameter set up and boundary conditions, the first part of the research was all about modeling the whole system where in this part the pipe with the defect, the CFRP wrapper with different lamination orientations and the 
repaired pipe with the wrapping material was designed and assembled so that it could be analyzed in the second part. The second part which is to evaluate and analyze the wrapping structure on defected pipe through various simulation where in this part the static analysis which covers various pressure parameters were evaluated by examining its stress, strain, factor of safety (FOS) and displacement. Later in flow simulation, the analysis that comprises temperature, pressure in pipe, and velocity along the pipe structure was done. The flow simulation is an additional analysis to justify that the CFRP could sustain the fluid flow upon maximum loading particularly at the repaired region.

Stage 1: Formulating the CFRP New Wrapping Structure

It is very important to set the parameters to carry out the research work to avoid any unavoidable incidents to occur. The parameter is referred to ASME-PCC-2-2018 (Mandatory Appendix Article 401-111-Short Term Pipe Spool Survival Test) and a PhD Thesis entitled Behavior of Repaired Composite Steel Pipeline Using Epoxy Grout as Infill Material [32]. The parameters were set for the pipe, defect, fluid boundary condition, and CFRP Wrapper. Table 3 tabulates the compilation parameters of pipe specification based on various references. As ASME B36.10M gives a minimum value for an Outside Diameter (OD) and therefore about $168.3 \mathrm{~mm}$ was chosen. Based on the OD the wall thickness, Nominal Pipe Size (NPS), Internal Diameter (ID) was found by referring to the pipe schedule table in ASME B36.10M. In the next level, the tensile strength and yield strength of the chosen pipe was chosen based on Table A-1 ASME B31.3. Other parameters were referred to LANL Engineering Standard Manual as realtime situation [33].

The design parameters for the defect were needed as a guide to evaluate the pipe integrity. For this research, the defect was set to be $100 \%$ wall loss. The test pressure was evaluated based on ASME-PCC-2-2018 (Mandatory Appendix Article 401-111) where the original outer diameter would be $168.3 \mathrm{~mm}$, the original thickness would be $7.11 \mathrm{~mm}$, and Yield Strength would be $235 \mathrm{MPa}$. While corrosion allowance was given into 4 specifications as per Table 4.

Table 5 tabulates the design parameters that should be considered during loading or setting up the boundary condition. These design parameters are from real case study. The parameters were given for both Imperial System and Metric System. The table provides all the limits for the design parameters where it comprises in accordance with corrosion allowance. Even though the calculation gives a bigger theoretical test pressure which is $19.65 \mathrm{MPa}$ based on ASME-PCC-2-2018 (Mandatory Appendix Article 401-

Table 3 Parameter set up for pipe specification

\begin{tabular}{|c|c|c|}
\hline Parameters & Specimen specifications & Parameter references \\
\hline Type of pipeline & Crude oil pipeline, operating & NA \\
\hline Outer diameter $(\mathrm{mm})$ & 168.3 & Minimum 150 mm (ASME B36.10M) \\
\hline Wall thickness (mm) & 7.11 & ASME B36.10M \\
\hline Nominal pipe size $(\mathrm{mm})$ & 150 & NPS range in between $1 / 8 "-12 "$ (ASME B36.10M) \\
\hline Pipe schedule & 40 & (ASME B36.10M) \\
\hline Internal diameter (mm) & 161.19 & {$[21]$} \\
\hline Length (mm) & 1200 & [21] \\
\hline Seamless pipe minimum & 245 & Table A-1 ASME B31.3 \\
\hline \multicolumn{3}{|l|}{ Yield strength $(\mathrm{MPa})$} \\
\hline $\begin{array}{l}\text { Seamless pipe tensile } \\
\text { strength (MPa) }\end{array}$ & 415 & Table A-1 ASME B31.3 \\
\hline Material grade & API 5L Grade B Carbon Steel Seamless & LANL Engineering Standard Manual [63] \\
\hline Fluid service & Normal & LANL Engineering Standard Manual [63] \\
\hline Fluid velocity & 2 to $10 \mathrm{~m} / \mathrm{s}$ & NA \\
\hline Pressure rating & Class 150 & ASME B36.10M \\
\hline $\begin{array}{l}\text { External pressure rating } \\
(\mathrm{MPa})\end{array}$ & 0.103421 & ASME B36.10M \\
\hline $\begin{array}{l}\text { Corrosion allowance (For } \\
\text { 6-inch pipe) }\end{array}$ & 0.063 & $0.00,0.031,0.063,0.125$ (ASME B36.10M) \\
\hline Type of pipe thickness & Thin wall structure (23.67) & $\begin{array}{l}\text { If ratio of pipe diameter to thickness is greater than } 20(\mathrm{D} / \mathrm{t}>20) \text { thin } \\
\text { wall structure is considered [22]. }\end{array}$ \\
\hline
\end{tabular}


Table 4 Theoretical defect parameters based on pipe specification

\begin{tabular}{|c|c|c|}
\hline Parameters & Defect specifications & Parameter references \\
\hline Type of defect & Crack & ASME-PCC0-2-2018 (Article 401-para 401-1.2.3) \\
\hline Size of defect & $100 \mathrm{~mm} \times 100 \mathrm{~mm} \times 7.11 \mathrm{~mm}(100 \%$ loss $)$ & NA \\
\hline Test pressure (MPa) & $\begin{array}{l}P_{f}=\frac{2 t s_{a}}{D} \\
P_{f}=19.65 \mathrm{MPa}\end{array}$ & $\begin{array}{l}\quad \text { ASME-PCC-2-2018 (mandatory appendix article 401-111 } \\
P_{f}=\text { testpressure } \\
\mathrm{S}_{\mathrm{a}}=\text { Yield STRENGTH } \\
\mathrm{D}=\text { Outer diameter } \\
\mathrm{t}=\text { Original thickness }\end{array}$ \\
\hline Required wall thickness $(t)$ & $\begin{aligned} t & =\frac{P D}{2(\mathrm{SE}+\mathrm{PY})}+A \\
t & =11.31 \mathrm{~mm}\end{aligned}$ & $\begin{array}{l}\mathrm{t}=\text { Required wall thickness, inches } \\
\mathrm{tm}=\text { minimum required wall }\end{array}$ \\
\hline $\begin{array}{l}\text { Minimum required wall } \\
\text { thickness }\left(t_{\mathrm{m}}\right)\end{array}$ & $\begin{array}{l}t_{m}=\frac{\mathrm{PD}}{2(\mathrm{SE}+\mathrm{PY})}+A \\
t_{m}=11.31 \mathrm{~mm}\end{array}$ & $\begin{array}{l}\text { thickness, inches } \\
\mathrm{P}=\text { Design pressure, MPa } \\
\mathrm{D}=\text { Pipe outside diameter, mm } \\
\mathrm{A}=\text { Corrosion allowance, mm } \\
\mathrm{S}=\text { Allowable Stress @ Design Temperature (100-300), psi (From } \\
\text { ASME B31.3, Table A-1) } \\
\text { E = Longitudinal-joint quality factor (From ASME B31.3, Table A- } \\
\text { 1B) } \\
\text { Y = Wall thickness correction factor (From ASME B31.3, Table } \\
\text { 304.1.1) assumed 0.5mm }\end{array}$ \\
\hline
\end{tabular}

Table 5 Fluid boundary condition [33]

\begin{tabular}{|c|c|c|c|c|c|c|c|c|}
\hline \multirow{2}{*}{$\frac{\text { Piping specification }}{\text { Imperial system }}$} & \multicolumn{8}{|c|}{ Corrosion allowance $(0.000,0.031,0.063,0.125)$} \\
\hline & Design pressure (psig) & 285 & 260 & 230 & 200 & 170 & 140 & 125 \\
\hline & Design temperature $\left({ }^{\circ} \mathrm{F}\right)$ & 100 & 200 & 300 & 400 & 500 & 600 & 650 \\
\hline & Minimum temperature $\left({ }^{\circ} \mathrm{F}\right)$ & 20 & 20 & 20 & 20 & 20 & 20 & 20 \\
\hline & Minimum test pressure (psig) & 430 & 390 & 345 & 300 & 270 & 245 & 220 \\
\hline & Maximum test pressure (psig) & 820 & & & & & & \\
\hline \multirow[t]{5}{*}{ Metric system } & Design pressure (MPa) & 1.97 & 1.79 & 1.59 & 1.38 & 1.17 & 0.97 & 0.86 \\
\hline & Design temperature $\left({ }^{\circ} \mathrm{C}\right)$ & 37.78 & 93.33 & 148.89 & 204.44 & 260.0 & 315.56 & 343.33 \\
\hline & Minimum temperature $\left({ }^{\circ} \mathrm{C}\right)$ & -6.67 & -6.67 & -6.67 & -6.67 & -6.67 & -6.67 & -6.67 \\
\hline & Minimum test pressure (MPa) & 2.96 & 2.69 & 2.38 & 2.07 & 1.86 & 1.69 & 1.52 \\
\hline & Maximum test pressure (MPa) & 5.65 & & & & & & \\
\hline
\end{tabular}

111), this research will also use the real case maximum test pressure at 5.65 $\mathrm{MPa}$ since this boundary condition is used in real cases [33]. For the temperature limit, the design temperature will be only set at maximum $343.3{ }^{\circ} \mathrm{C}$, while the minimum design pressure will be set to $37.78^{\circ} \mathrm{C}$. At the same time, the minimum test temperature was set at $-6.67{ }^{\circ} \mathrm{C}$. This was decided to be used as the case study has maximum test pressure below the theoretical maximum test pressure. It should be noted that Maximum Allowable Working Pressure (MAWP) is the highest level of pressure that it could be exposed to, while the design pressure is the highest level of pressure it should be exposed to in normal operating conditions $[34,35]$. Whenever a wrapper could sustain the MAWP itself, it eventually indicates that it could sustain any pressure below than the MAWP [32].

The schematic drawing of the defect on the pipe is illustrated in Fig. 7. Since this research focusses on repairing the fully defected pipe, the wall loss WAS set to be at $100 \%$. The defect with a dimension of $100 \times 100 \times 7.11 \mathrm{~mm}$ thru wall was designed right at the center of the pipe due to corrosion. Although theoretically there are various type of defects, this research only focusses the crack type defect. The geometry of the defect was designed as per the defect parameters.

The parameter for the CFRP wrapper was identified too as a guideline for evaluating the wrapper's performance with analysis. The minimum wrap thickness of the CFRP 


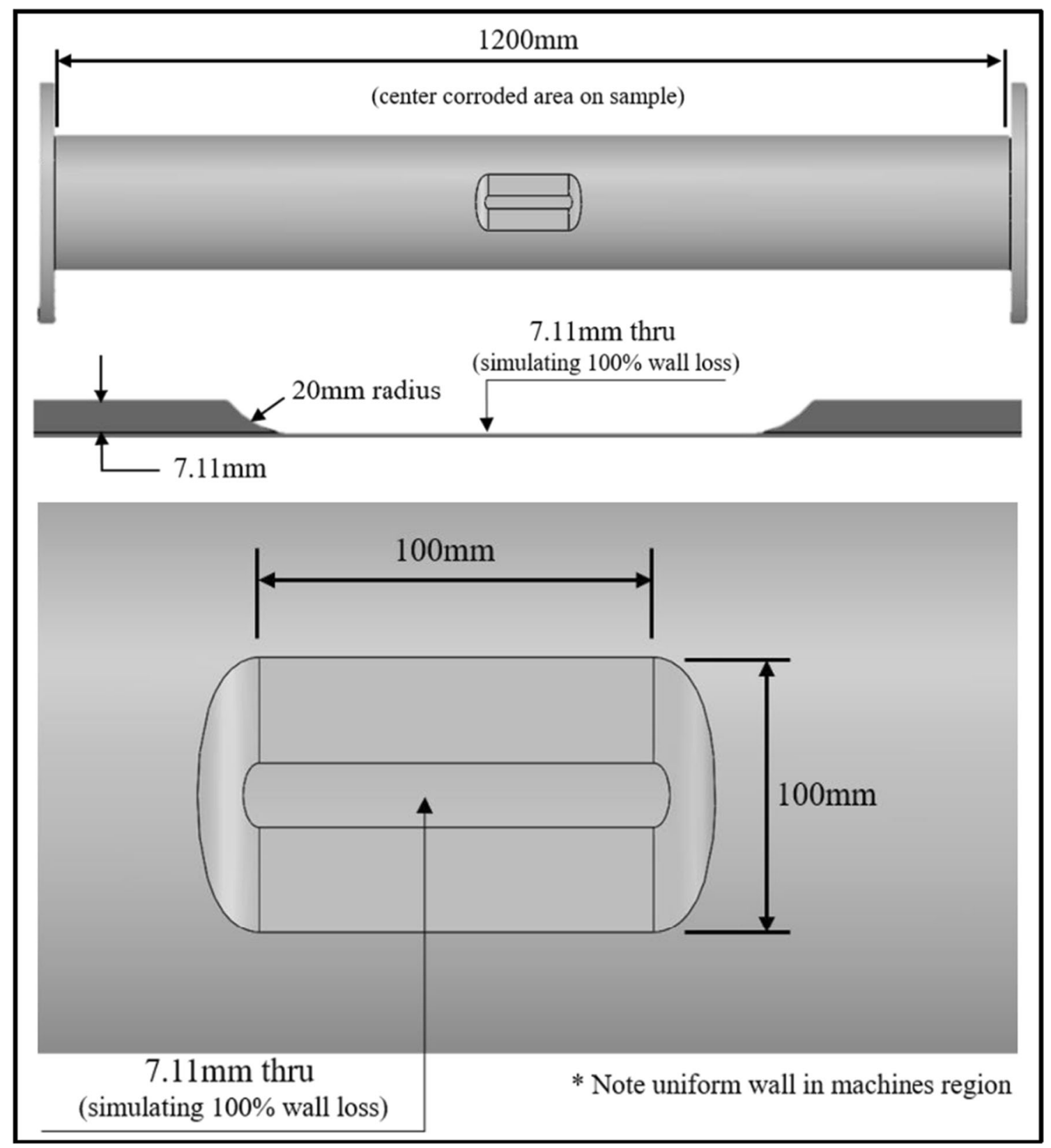

Fig. 7 Schematic diagram of defected pipe

layer and the length of layer beyond the damaged region was found from Formula 1, Formula 2, and Formula 3 in Table 6. Table 6 shows the parameters for carbon fiber reinforced polymer that was considered during the repairing of defected pipe.

Material properties of the pipe, sealer and CFRP Wrapper were established first before starting up the simulation. The pipe material is a metallic material specifically referring to API 5L Grade B Carbon Steel which is known as isotropic type material. The same material properties were used for the sealer. The use of sealer is very common in real cases. It is used to improve both pipe strength and CFRP wrapping geometry structure. The CFRP is considered as orthotropic material since this composite material has various layer which will possess different properties in different layer [36, 37]. These parts' material properties need to be declared as SolidWorks required to key in those properties manually in the Material List. Some assumptions have been made where the Elastic Modulus and the Thermal Expansion Coefficient were referred according to general properties of Carbon Steel [38]. Designing the defected pipe with proper geometries in accordance with the parameters that were listed in Tables 
Table 6 CFRP wrapping structure parameters

\begin{tabular}{|c|c|c|c|}
\hline Wrapper specification & \multicolumn{2}{|l|}{ Research parameters } & Parameters reference \\
\hline Wrapping material type & \multicolumn{2}{|l|}{$\begin{array}{l}\text { Carbon fibre reinforced polymer } \\
\text { (Standard) }\end{array}$} & ASME-PCC0-2-2018 (Article 401-1.1.3) \\
\hline CFRP density $\left(\mathrm{kg} / \mathrm{m}^{3}\right)$ & \multicolumn{2}{|l|}{1600} & \\
\hline Tensile strength of CFRP (GPa) & \multicolumn{2}{|l|}{3.53} & NA \\
\hline Elastic modulus of CFRP (GPa) & \multicolumn{2}{|l|}{230} & NA \\
\hline Minimum wrapping thickness (mm) & $\begin{array}{l}t_{\min }=\frac{1}{E_{c^{\varepsilon c}}}\left(\frac{P D}{2}-s t_{s}\right)(1) \\
\text { Maximum test Pressure }(\mathrm{MPa}) \\
5.65 \text { (practical) } \\
19.65 \text { (theoretical) }\end{array}$ & $\begin{array}{l}t_{\min }(\mathrm{mm}) \\
0.13 \\
0.47\end{array}$ & $\begin{array}{l}E_{c^{\varepsilon_{c}}}=\text { ultimate tensile strength } \\
\mathrm{P}=\text { Test pressure } \\
\mathrm{D}=\text { Outer diameter } \\
\mathrm{s}=\text { Pipe yield strength } \\
t_{s}=\text { Remaining wall thickness }\end{array}$ \\
\hline $\begin{array}{l}\text { Length of wrapper extended beyond damaged region } \\
(\mathrm{mm})\end{array}$ & \multicolumn{2}{|l|}{$L_{\mathrm{over}}=2.5 \sqrt{\frac{D t}{2}}(2)$} & $\begin{array}{l}\mathrm{t}=\text { required wall thickness, inches } \\
\mathrm{D}=\text { Pipe outside diameter, } \mathrm{mm}\end{array}$ \\
\hline Total axial length/repair length & \multicolumn{2}{|c|}{$L=2 L_{\mathrm{over}}+L_{\mathrm{defect}}+2 L_{\mathrm{taper}}(3)$} & $\begin{array}{l}L_{\text {defect }}=\text { Defect length } \\
L_{\text {taper }}=\text { Taper Length }(87.3 \mathrm{~mm})\end{array}$ \\
\hline
\end{tabular}

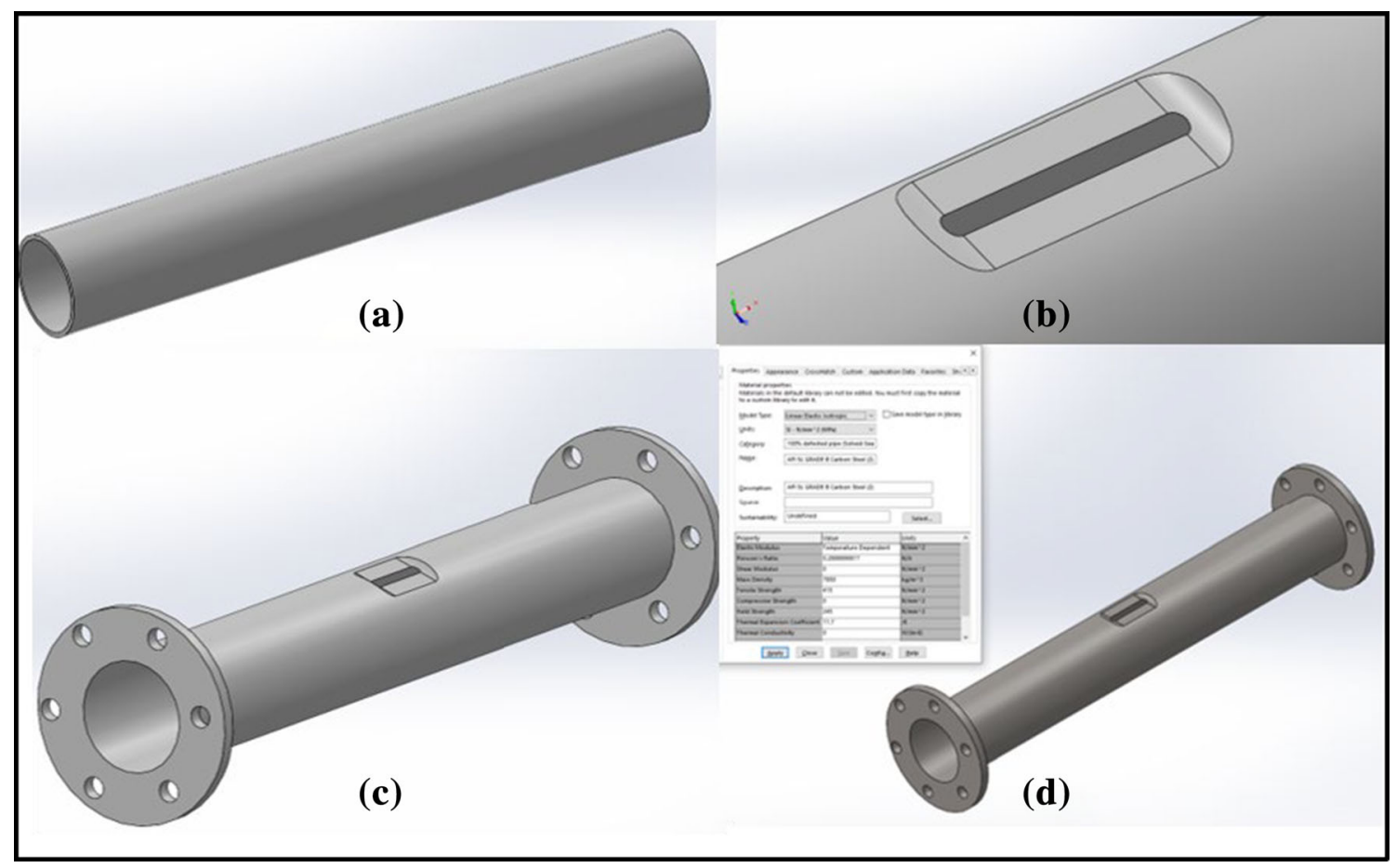

Fig. 8 (a) Pipe design without defect, (b) Sketch the defect on the pipe, (c) Design the flanges for the pipe, (d) Apply material properties for the pipe

$3,4,5$, and 6 . Figure 8 is the steps in designing the $100 \%$ defected pipe.

Based on the figure above, the sealer was designed to wrap the defected region to separate the fluid region with solid region. The SolidWorks wrapper design is needed to improve the mechanical strength of pipe through CFRP Wrapper. The designing process of the wrapper with proper geometries is listed as per the procedure below and Fig. 9.
Stage 2: Analysis on Repaired Defected Pipe by CFRP Wrapping Structure

Right after all the parts were assembled, the performance of the wrapper was evaluated through analysis in SolidWorks software. In this second stage, the static analysis and flow simulation analysis were evaluated on the performance of CFRP as wrapping structure. The static 

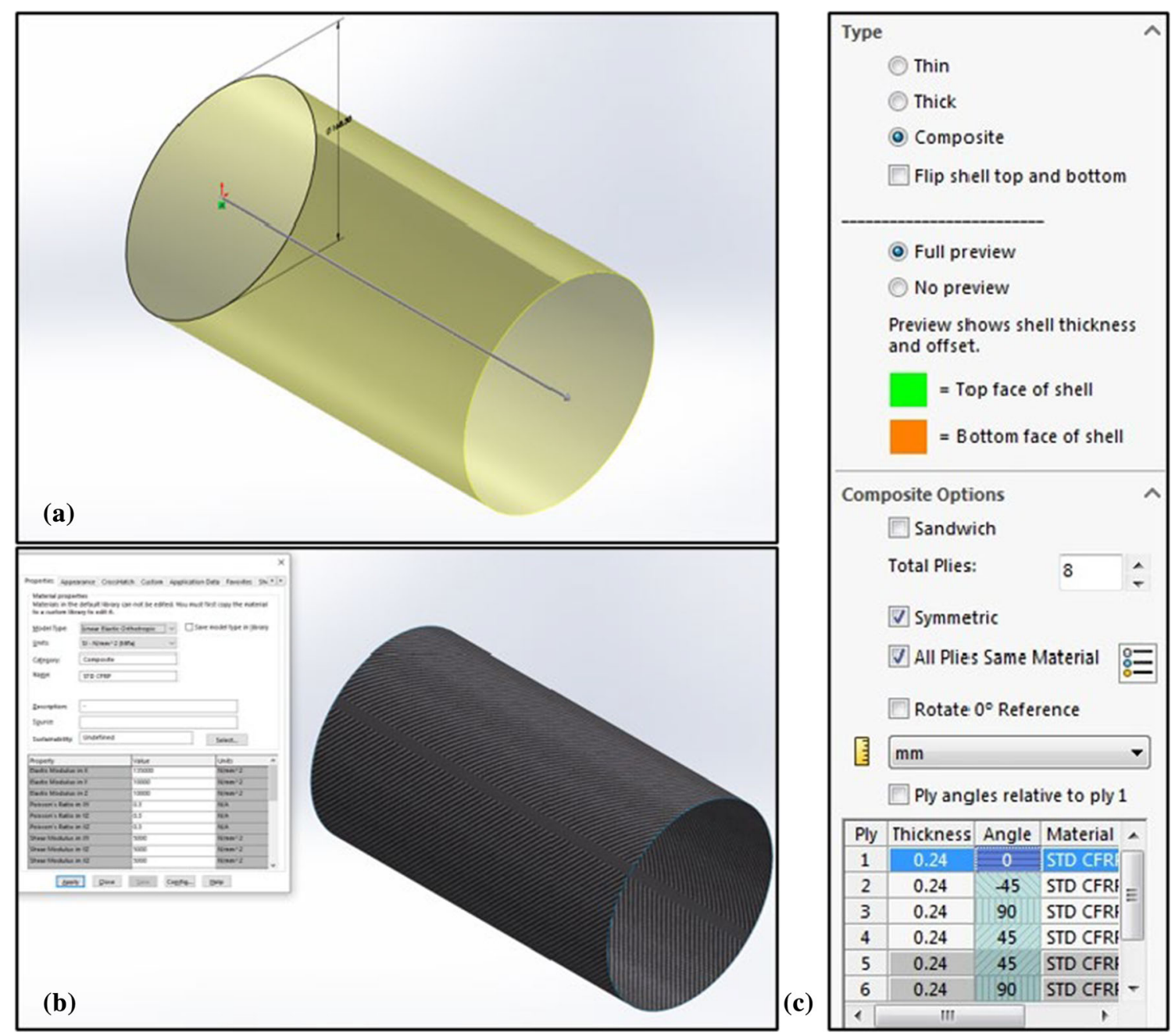

Fig. 9 (a) Dimension and surface feature of wrapper, (b) material Properties of CFRP Wrapper, (c) CFRP Lamination Angle Optimization

analysis was done at first place to make sure that the wrapper could withstand the pressure parameters that were given by the standards and followed by the flow simulation to make sure that there were no leakages after wrapping. Since any wrapper could wrap the pipe leakage, it is necessary to choose the best. So, static analysis was done to differentiate and identify the best one and verify its performance to resolve the leakages problem through the flow simulation. The flow simulation is only available if the whole structure is fully watertight which indicates that there are no leakages after the repair using suitable wrapping structure [39].

The static analysis was only focused on the performance of the wrapper by loading various internal pressures in the pipe along with fix geometry and connections. The reason on selecting the static analysis among other type of analysis is due to the assumption that was made earlier that the internal force or the internal pressure of the pipe is constant where it is assumed as quasi-static [40]. Talking about the fix geometry and connections, both were considered as very important conditions before running the simulation. Based on Fig. 13, it could be seen that the fix geometry was set at the holes where in real situations bolts are used to connect the other pipe segments. So, it is logic to define the holes as fixed geometry . Contact settings describes the interaction between part boundaries that are initially contacting or come into contact during loading [41]. This contact was declared as the CFRP wrapper, and the sealer will be attached to the defected pipe specifically at the defected region. Since this research concerns on the internal pressure, therefore the pressure is applied throughout the inner region of the pipe as could be seen in Fig. 10.

The parameter set up that was tabulated in Tables 3, 4, 5, and 6 was used as inputs elements. The next move was developing the finite element model through meshing before running the static analysis based on the geometries of individual parts (steel pipe, sealer, and composite). The 


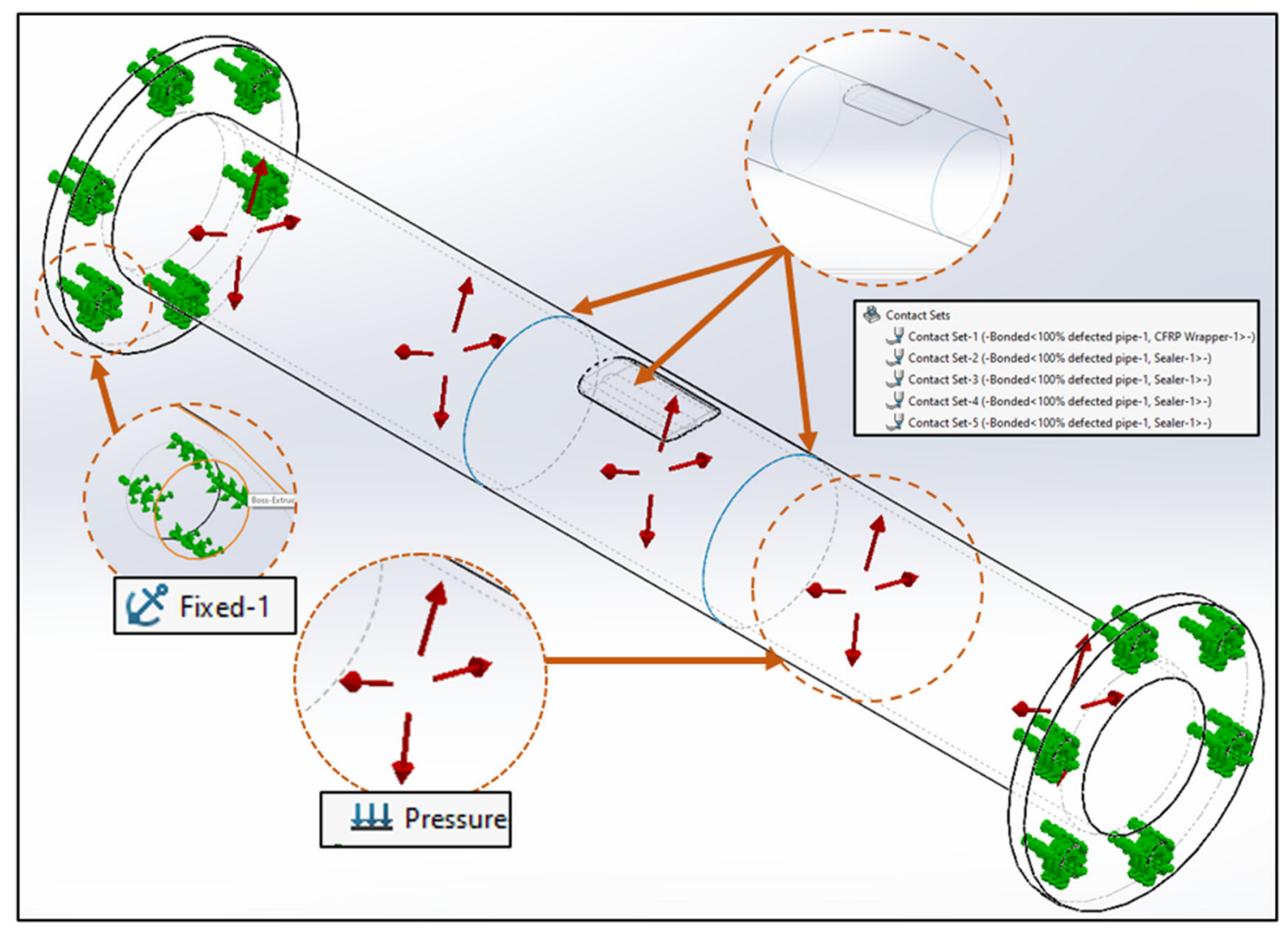

Fig. 10 The use of fixed geometry, contact set and internal pressure for static analysis

geometrical modal of the 3 parts can be obtained from the modal that was developed and assembled earlier. The importance of the Finite Element Analysis is to study the CFRP performance as a wrapping material for nodal analysis so that the CFRP performance can be analyzed precisely [42]. Each created part was assembled as such that it can be analyzed as an integrated structure. For composite repair pipes, the interactions between all parts (bonding properties) must be modeled with comply with suitable boundary condition and with acceptable internal pressure. A proper meshing size was assigned to generate mesh for all parts. The meshed parts at this stage are ready to be analyzed where the property of CFRP as wrapping material could be evaluated with its performance. Since SolidWorks simulation provides default meshing through Mesh Property Manager, it makes the whole meshing process very easy. Although the default meshing could be done but it is very necessary to have the 'Control Mesh' so that fine mesh could be achieved in critical geometries. The general mesh of the whole structure was achieved as illustrated in Fig. 11a, while b illustrates the control mesh region in the overall structure.

Right after the mesh was made the analysis was ran. The static analysis could also be made by just selecting the Mesh and Run option. With proper meshing, boundary condition, and proper loading, the analysis was done with right memory cache. The sample final output or the results are illustrated in Fig. 12. The results covered the stress, strain, displacement, deformed results, and Factor of Safety (FOS).

Right after static analysis, the research proceeds with Fluid Simulation Analysis/CFD Analysis. The aim of CFD analysis was taken into consideration as it will give a better visualization and analysis of fluid flow in a defected pipe. Simulating the fluid flow in the repaired pipe will validate the performance of repaired pipe with CFRP lamination with different lamination orientation. Upon setting up all the boundary conditions of the pipe and fluid, the simulation based on pressure, velocity, temperature, and the parameter distribution along the pipe was evaluated. There were 3 surface boundaries was set where it consists of Inlet (for inflow), Outlet (for outflow), and wall.

Some assumptions were made earlier where the type of flow was assumed to be steady state, and it was considered as isothermal and laminar, no turbulence or heat transfer models were applied. The flow was simulated under a constant pressure drop to allow the simulation to predict any changes in the flow rate on repaired pipe. The use of a pressure boundary condition at the inlet also allowed the CFD analysis to impose the fully developed velocity profile 


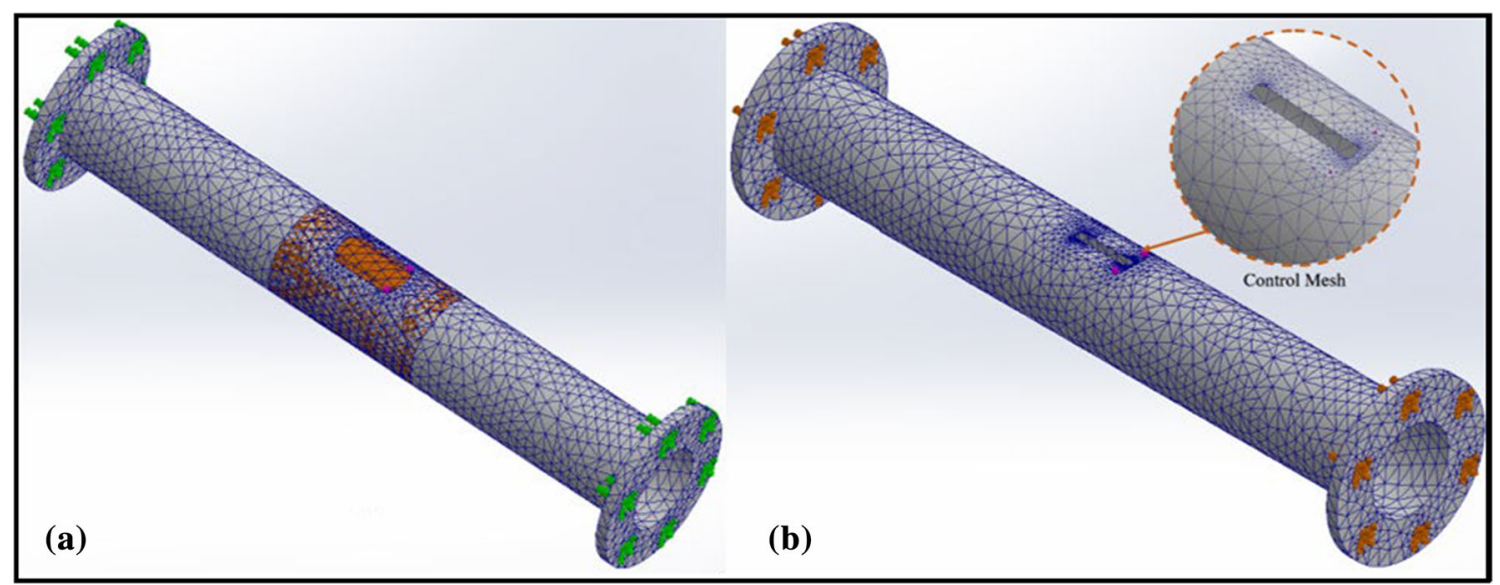

Fig. 11 (a) The general mesh of whole structure, (b) the control mesh at defected region

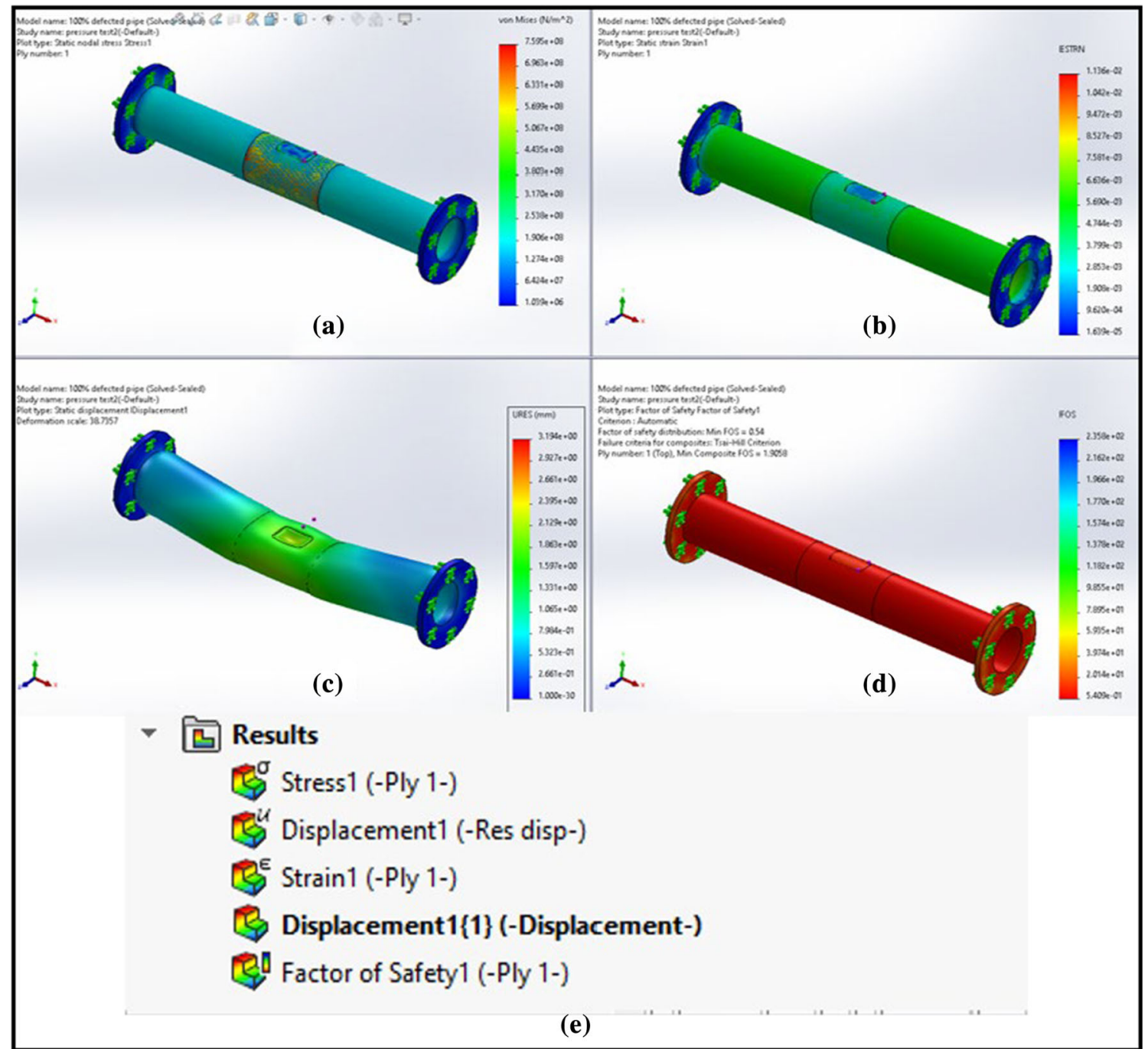

Fig. 12 (a) The sample stress results, (b) the sample strain results, (c) the sample displacement results, (d) the sample factor of safety results, (e) the list of results that could be achieved by static analysis 
at the inlet, thus ensuring a fully developed flow throughout the pipe and avoiding the need for a long pipe. At the inlet, a static pressure equal to the total pressure drop along the pipe was specified; the boundary condition at the outlet was then a zero-static pressure [39]. Moreover, since the flow simulation could be only run when the whole geometry is enclosed, the lid feature in the flow simulation was used to close all the openings. Once the structure was enclosed, the structure was ready as it is eligible to run the analysis. As the first step, the fluid type with its properties was inserted via the "Wizard" option. The range of Design Pressure and Design Temperature that was considered in CFD analysis was based on Table 5 earlier. Only 2 boundary conditions were considered for the fluid in the pipe segment where the inlet velocity and total pressure was used as illustrated in Fig. 13.

Right after all the boundary conditions have been applied, there were multiple analysis was achieved through various flow simulation. For this research, the flow simulation covers on cut plots, surface plots, and flow trajectories as illustrated in Fig. 14. The major parameters that were focused were the pressure, temperature, and fluid velocity. The cut plot provides the results at the region while the flow trajectories provide the fluid flow either throughout the pipe or region. The surface plot provides the parameter transmission toward the surface [29]. It plays a better role in analyzing the exposure on the surface.

\section{Results and Discussions}

As mentioned earlier the static analysis plays a significant role in deciding the right wrapping structure, under constant pressure loading in the whole pipe structure. Indeed, the flow simulation was performed to verify the wrapping structure's performance toward the fluid flow. Table 7 is about the parameters and orientations that was used to simulate and analyze the performance of the CFRP Wrapper. All the analysis was analyzed and evaluated visually and numerically.

\section{Static Analysis}

In static analysis, the visual inspection and numerical analysis that cover the strain, deformed results, stress, and FOS were evaluated. This is just to make sure that the numerical results do not have conflicts toward the visual inspection. In this part, the GFRP wrapper was also simulated to compare the performance of both wrappers with the same lamination orientation. As the sealer was attached at first before CFRP was wrapped around the defected region, the pipe and the CFRP structure didn't deform outward since the sealer withstands the pressure at first. The CFRP was indeed acts as a support structure for the sealer to sustain any pressure. The usage of sealer is a common practice too in pipe repairing method where the sealer would be used to seal the defect to sustain the leakages for short term till the wrapper will be wrapped surrounding it [32]. The difference in between the defected pipe with and without sealer is illustrated in Fig. 15. It is obvious to see the difference in between the two situations. It proves that the sealer functions as a boundary to sustain any leakage for a short term. In real case, the sealer will be welded to the surface. For simulation purpose, the 'Connection Set Bonded' was used.

With all the design and test parameters was loaded, the performance of the CFRP Wrapper was evaluated. The maximum layer that could be used was 8 layers due to symmetric lamination, and minimum layers were 2 layers as composite option is only available with those 2 plies only in SolidWorks. The unidirectional orientation (UD) indicates that all the polymer matrixes were aligned at same angles. So, the UD orientation of $\left(0^{\circ}\right)_{n}$ was evaluated right from 2 plies till 8 plies. The 3-type symmetric

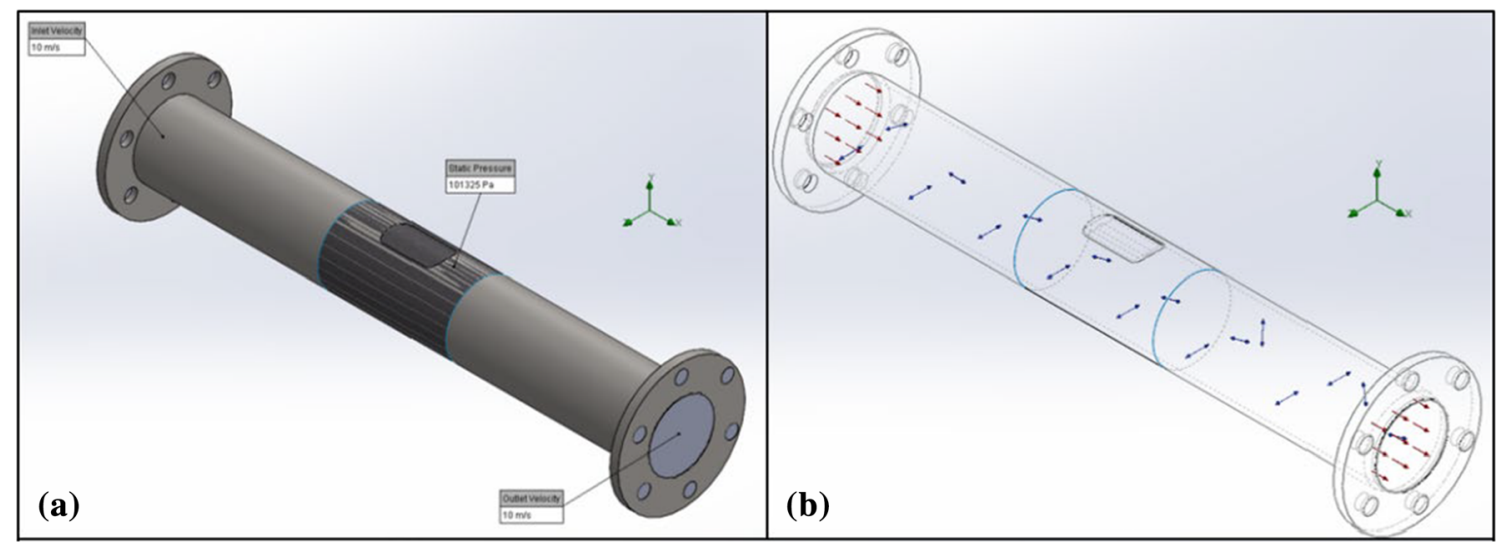

Fig. 13 (a) The inlet velocity and total pressure, (b) the overall boundary conditions 


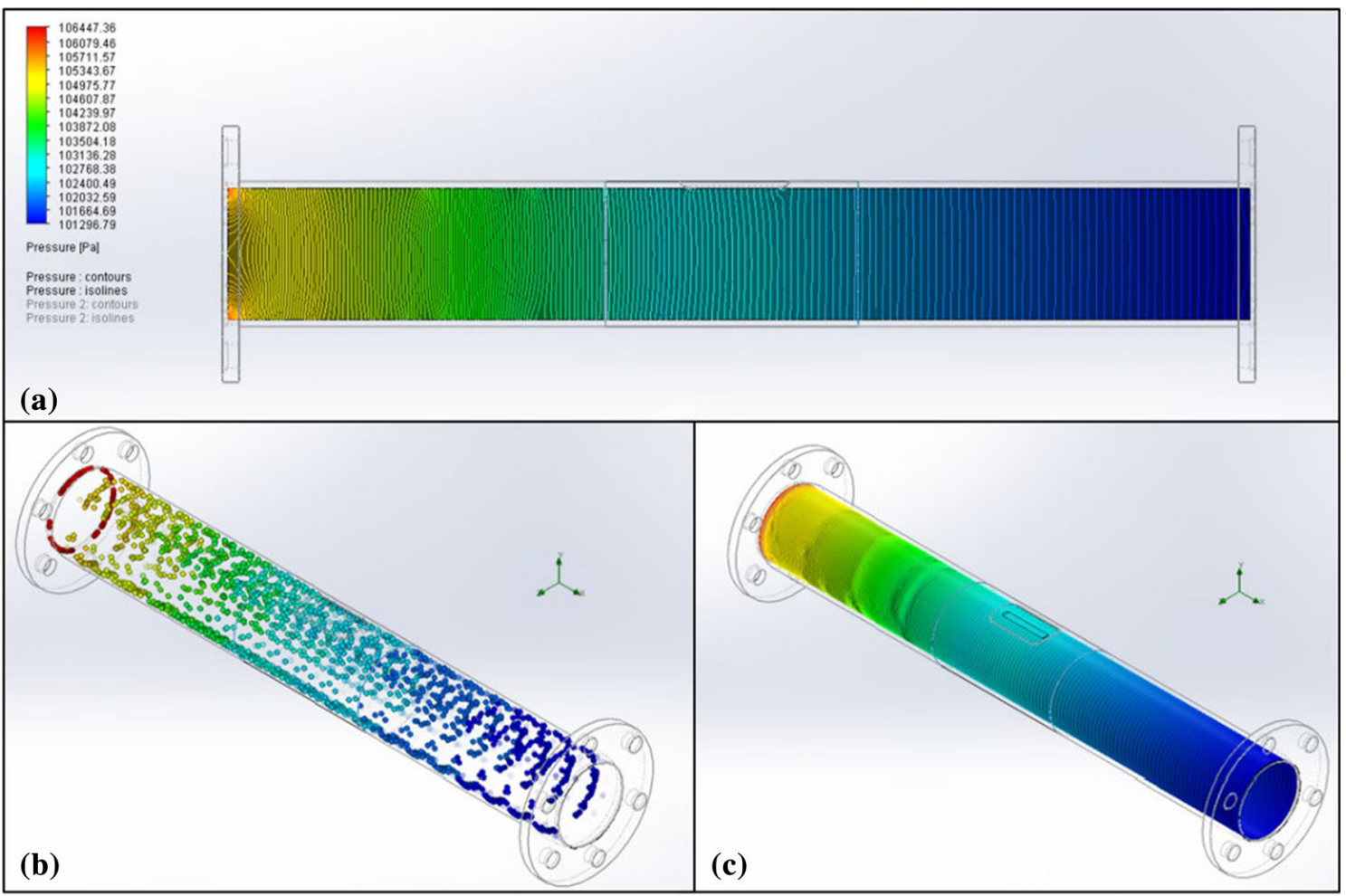

Fig. 14 (a) The Cut Plots, (b) the flow trajectories, (c) the surface plots

Table 7 The orientation and the parameters

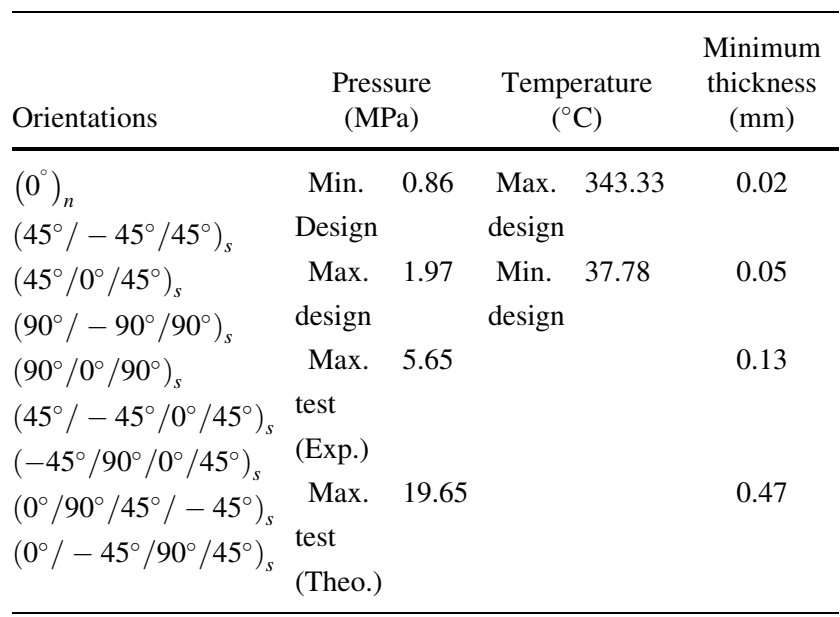

orientation of $\left(45^{\circ} /-45^{\circ} / 45^{\circ}\right)_{s}, \quad\left(45^{\circ} / 0^{\circ} / 45^{\circ}\right)_{s}$ $\left(90^{\circ} /-90^{\circ} / 90^{\circ}\right)_{s},\left(90^{\circ} / 0^{\circ} / 90^{\circ}\right)_{s}$ were evaluated at only 6 plies due to 3 symmetric orientations. Moreover, the 4-type symmetric orientation of $\left(45^{\circ} /-45^{\circ} / 0^{\circ} / 45^{\circ}\right)_{s}$, $\left(-45^{\circ} / 90^{\circ} / 0^{\circ} / 45^{\circ}\right)_{s}, \quad\left(0^{\circ} / 90^{\circ} / 45^{\circ} /-45^{\circ}\right)_{s}, \quad$ and $\left(0^{\circ} /-45^{\circ} / 90^{\circ} / 45^{\circ}\right)_{s}$ were evaluated at only 8 plies due to 4 symmetric orientations. All the material properties of all the plies were set to be the same which uses the Standard CFRP properties. To evaluate the performance of the CFRP Wrapper, it is very important to analyze the stress, resultant displacement, and strain of the unrepaired defected pipe. Table 8 is the summary of the static analysis of the unrepaired defected pipe.

Based on the table above, it is obvious that the minimum, maximum stress and strain of the pipe will increase when the pressure increases. It is quite convincing where the defect had eventually caused the internal pressure to escape to the surrounding through it. If the internal pressure increases obviously stress and strain in the pipe will increase particularly at the defect, as most of the pressure may escape through the defect due to low pipe mechanical strength particularly at that defected region [43, 44]. Moreover, the defect eventually grows bigger in size upon an increase in pressure loading. It seems the defect had displaced more when the pressure is at maximum [45]. Upon looking at the static analysis on the defected pipe it clearly shows that a wrapper is needed to repair the defect as possible it could.

Therefore, all the design and test parameters were loaded again, and they were evaluated from stress, strain, FOS, and displacement parameters but this time with proper wrapping structure. The overall performance of the CFRP wrapper was analyzed by compiling all the static analysis results. The performance of the CFRP lamination orientation was evaluated based on two properties that is the maximum stress on the CFRP wrapped pipe and the minimum safety factor of it. The lowest maximum stress 

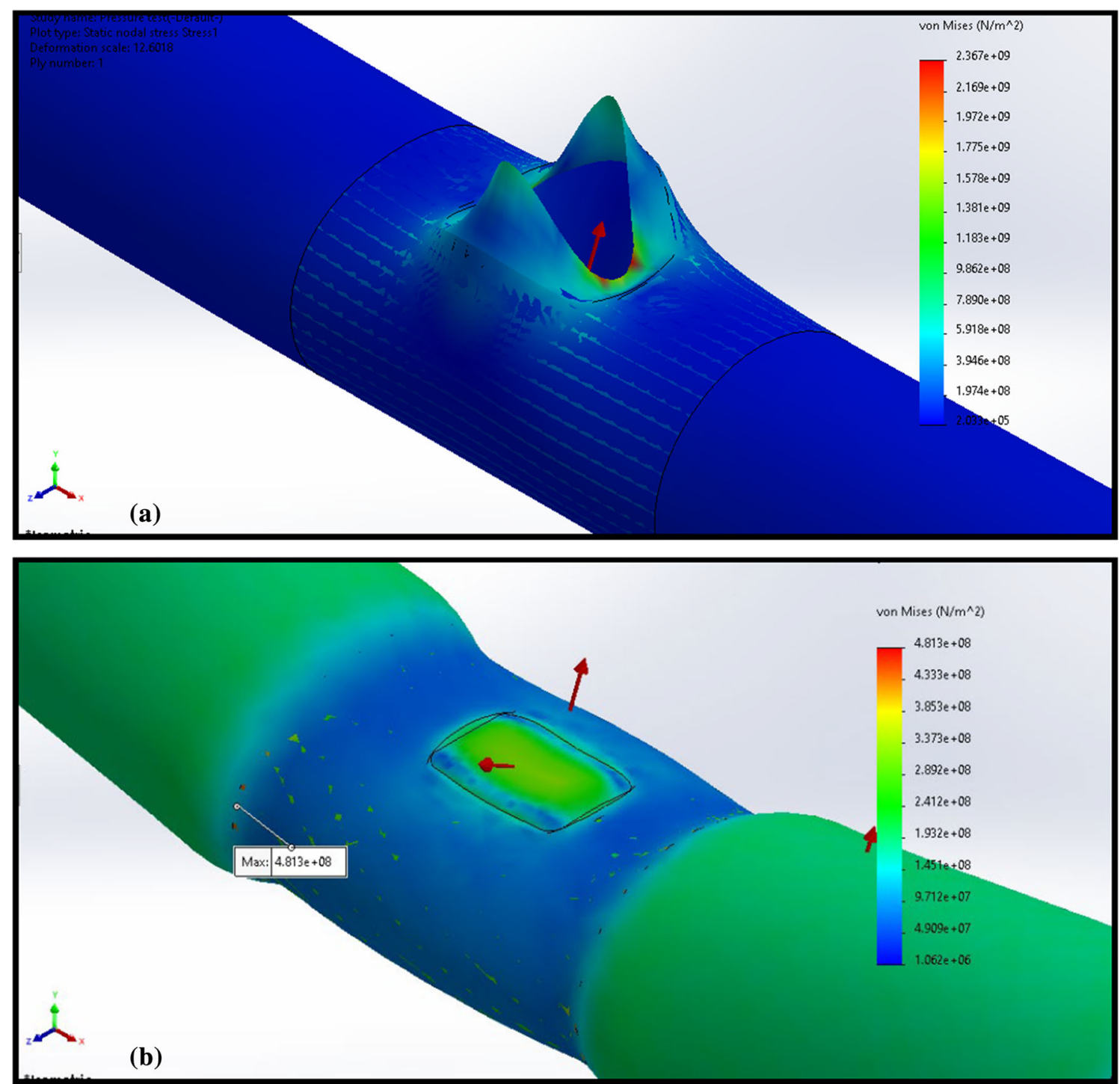

Fig. 15 (a) Pipe structure without sealer, (b) pipe structure with sealer

Table 8 The summary of the static analysis unrepaired defected pipe

\begin{tabular}{|c|c|c|c|c|c|c|}
\hline \multirow[b]{2}{*}{$\begin{array}{l}\text { Presssure } \\
(\mathrm{MPa})\end{array}$} & \multicolumn{2}{|c|}{ Stress $(\mathrm{MPa})$} & \multicolumn{2}{|c|}{$\begin{array}{c}\text { Resultant } \\
\text { displacement } \\
(\mathrm{mm})\end{array}$} & \multicolumn{2}{|c|}{ Strain } \\
\hline & $\begin{array}{l}\text { Min@ } \\
\text { Node: } \\
15406\end{array}$ & $\begin{array}{c}\text { Max } \\
@ \\
\text { Node: } \\
22576\end{array}$ & $\begin{array}{c}\text { Min } \\
@ \\
\text { Node: } \\
1\end{array}$ & $\begin{array}{l}\text { Max } \\
@ \\
\text { Node: } \\
22608\end{array}$ & $\begin{array}{c}\text { Min@ } \\
\text { Element: } \\
14428\end{array}$ & $\begin{array}{c}\text { Max@ } \\
\text { Element: } \\
14704\end{array}$ \\
\hline 0.86 & 0.049 & 363.6 & 0.00 & 0.994 & $1.186 \mathrm{e}-06$ & $4.918 \mathrm{e}-03$ \\
\hline 1.97 & 0.113 & 832.8 & 0.00 & 2.276 & $2.717 \mathrm{e}-06$ & $1.127 \mathrm{e}-02$ \\
\hline 5.65 & 0.323 & 2388 & 0.00 & 6.529 & $7.792 \mathrm{e}-06$ & $3.231 \mathrm{e}-02$ \\
\hline 19.65 & 1.136 & 8395 & 0.00 & 22.95 & $2.739 \mathrm{e}-05$ & $1.136 \mathrm{e}-01$ \\
\hline
\end{tabular}

was considered to make sure that the lamination orientation could withstand the high-pressure load [45]. On the other hand, the lowest maximum stress would give a huge amount of stress differences that was reduced. Indeed, the wrapper also need to have the highest value of minimum safety factor so that it will have better properties in higher pressure in the least safety factor [46]. It is true that higher safety factor would give less probability of failure, but it should also be considered the cost, time and effort that is involved in pipe repairing [47]. Therefore, expecting higher safety factor from the minimum prospect will eventually consider the cost and the effort to execute the CFRP Wrapping Structure. All the results were compiled and graphed as per Fig. 16.

Figure 16 is about the overall maximum stress that was achieved based on various pressures toward the lamination orientations. The CFRP lamination orientations that has the lowest maximum stress right from maximum pressure were 
Maximum Stress On Repaired Pipe (MPa)

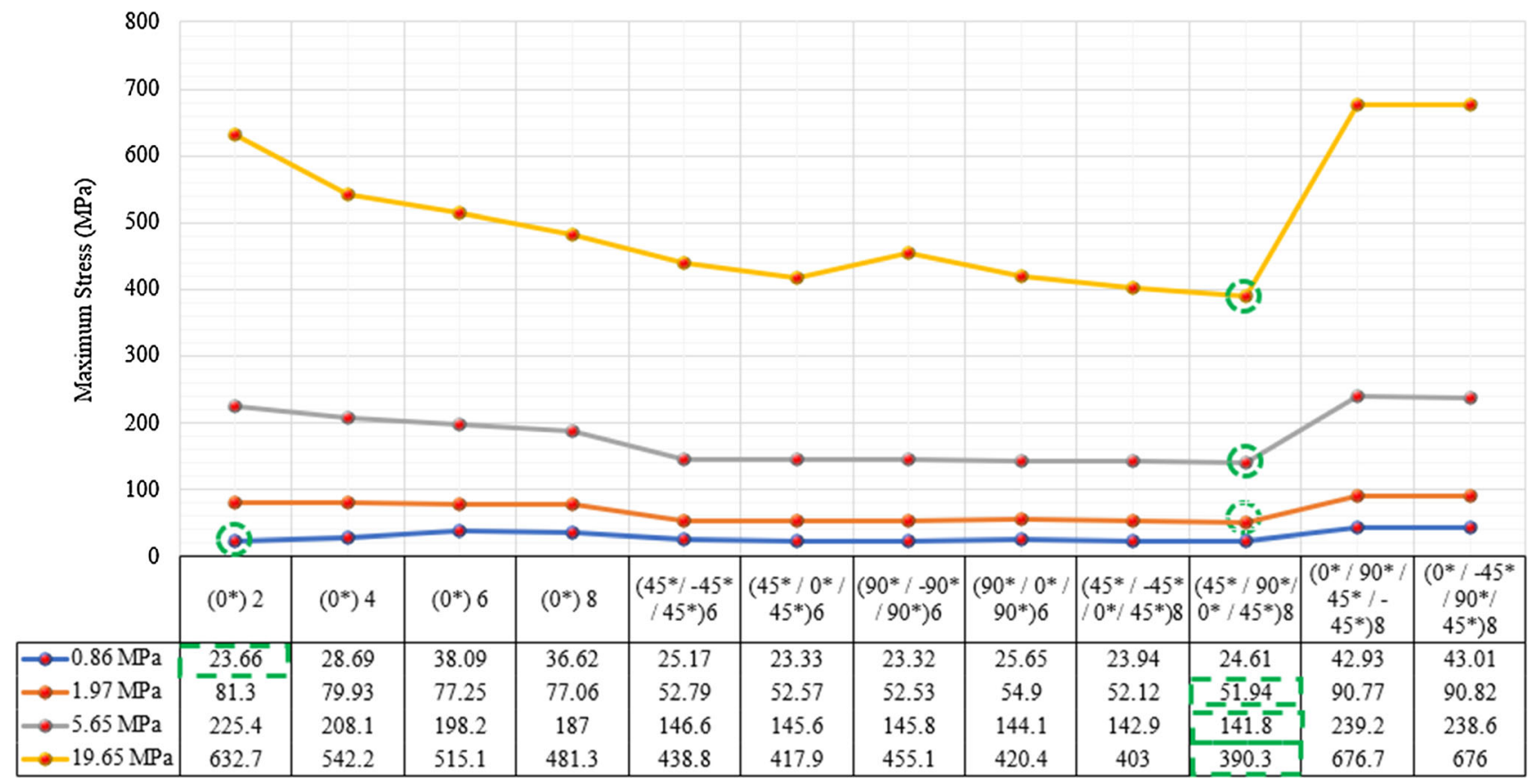

Fig. 16 The graph of maximum stress on CFRP wrapped defected pipe against the CFRP lamination orientation

given the priority. This was due to the reason that a wrapping structure would be used to wrap a defect that could withstand higher pressure. That's the reason all the CFRP parameters that were stated earlier were assumed to be at maximum level so that it could withstand higher pressures. The strain property was not much given priority as almost all the pipe repaired structure were having very minimal strain. Even the resultant displacement was also given the least priority as all the wrappers performed well against the fluid pressure and comparatively almost all the displacement were very close to each other, and all of it is below than $10 \mathrm{~mm}[23,48]$.

As per the graph, the minimal stress among the other stresses that were exerted by each CFRP lamination was identified. Even though the lamination orientation of $\left(0^{\circ}\right)_{2}$ exerts lesser stress at $0.86 \mathrm{MPa}$ (minimum design pressure) at only $23.66 \mathrm{MPa}$, but the orientation performance of $\left(45^{\circ} / 90^{\circ} / 0^{\circ} / 45^{\circ}\right)_{s}$ under the maximum test and design pressure was remarkable. It was obvious to analyze that the CFRP Lamination of $\left(45^{\circ} / 90^{\circ} / 0^{\circ} / 45^{\circ}\right)$ s exhibits the least stress among other stresses in each pressure instance. When the internal maximum design pressure was $1.97 \mathrm{MPa}$, the wrapper exerted only $51.94 \mathrm{MPa}$ of stress and during the maximum real test pressure which was $5.65 \mathrm{MPa}$, about 141.8 MPa stress was exerted by the repaired pipe structure. Things gets very interesting when the pipe structure was able to withstand the theoretical maximum test pressure which was $19.65 \mathrm{MPa}$, with a very minimal stress about $390 \mathrm{MPa}$ without any tear. Although CFRP lamination orientation $\left(45^{\circ} / 90^{\circ} / 0^{\circ} / 45^{\circ}\right)_{s}$ possess better properties in reducing the maximum but still the safety factor should need to be considered. The FOS is very important to be considered as a wrapper should not only able to reduce the maximum stress but also safer during service. The FOS will eventually differentiate the safer wrapper among the wrappers that could effectively reduce the maximum stress on the defected region. The safety factor of all the CFRP Wrapper was plotted in Fig. 17.

Surprisingly based on Fig. 17, the same $\left(45^{\circ} / 90^{\circ} / 0^{\circ} / 45^{\circ}\right)_{s}$ orientation exerted the higher value in minimum FOS. Therefore, this lamination orientation was able to reduce the maximum stress to least and possess higher value in minimum FOS. By going through all the data that were generated after simulating the unrepaired defected pipe and repaired defected pipe, it is so obvious that all the CFRP wrapper reacts positively toward the internal pressure through the defect. All the wrapper deforms toward inward even though all the pressures were toward outward. Interestingly, the pipe structure withstands the pressure subject to the lamination orientation. As the research manage to simulate the right lamination orientation but an extra step was taken to compare the CFRP's performance relative to GFRP wrapper with the same $\left(45^{\circ} / 90^{\circ} / 0^{\circ} / 45^{\circ}\right)_{s}$ orientations. Figures 18 and 19 are the graphs that compare the CFRP and GFRP from maximum stress and minimum FOS perspectives. 


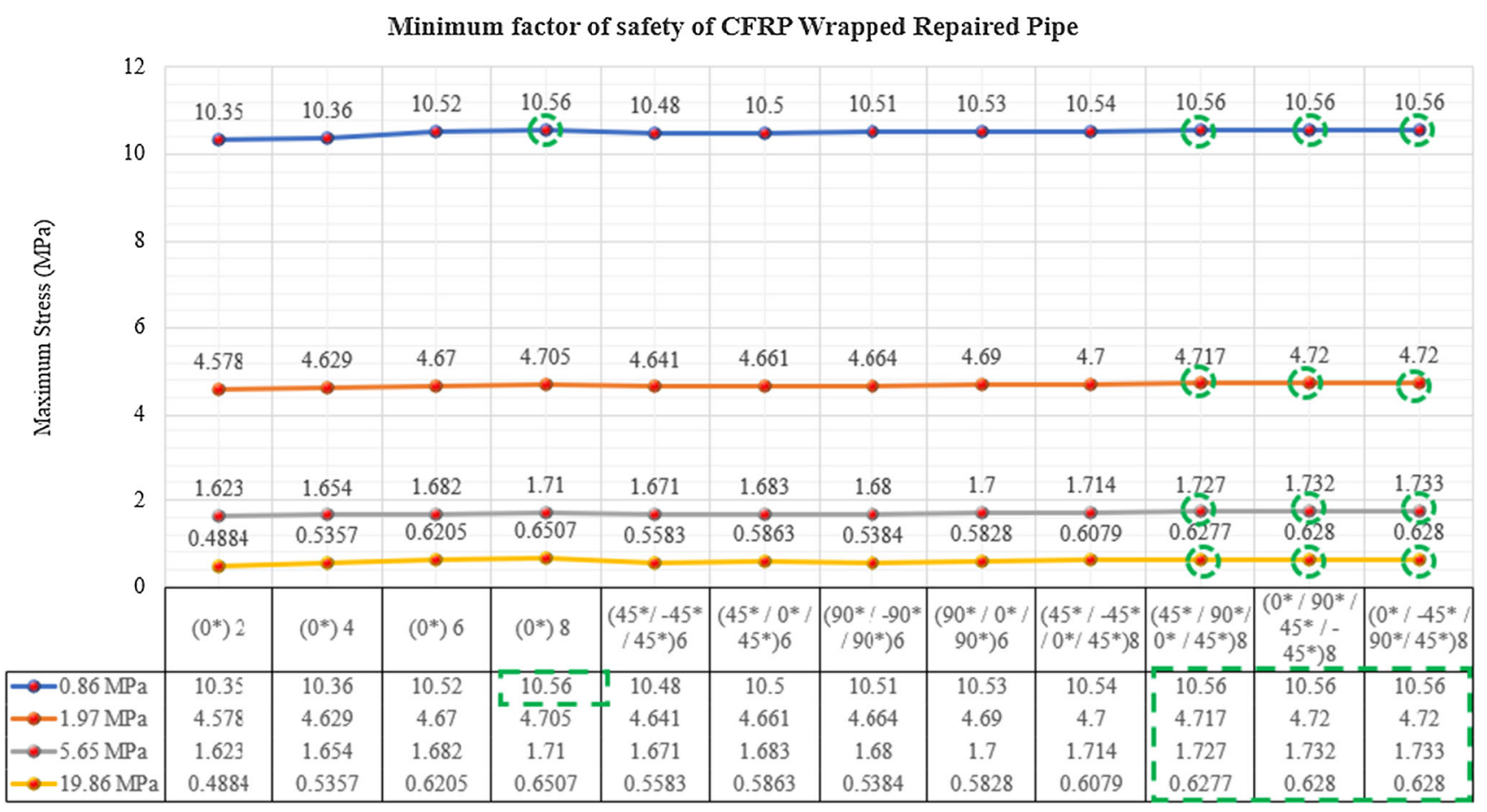

Fig. 17 The graph of minimum factor of safety of CFRP wrapped defected pipe against the CFRP lamination orientation

\section{Maximum Stress On Repaired Pipe}

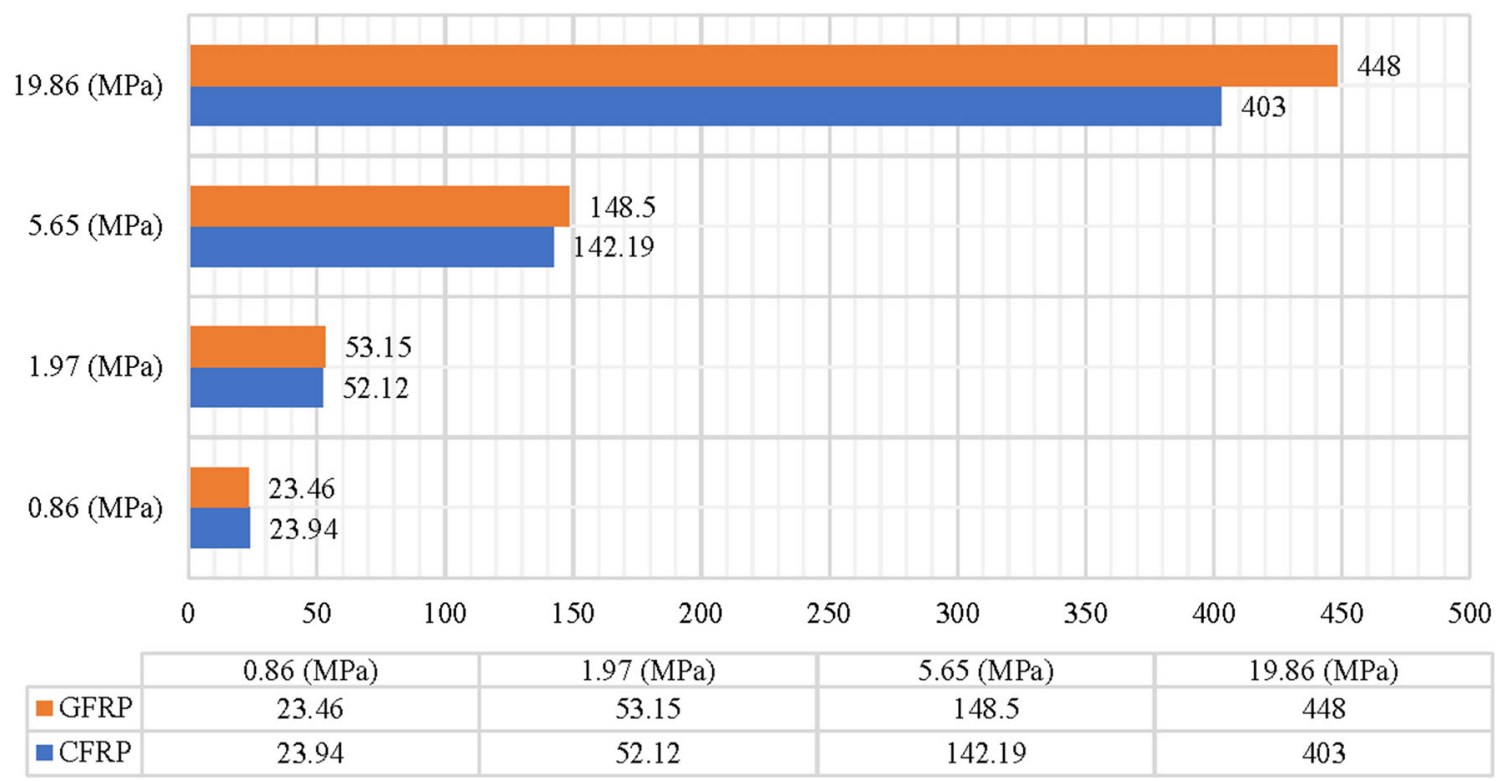

Maximum Stress (MPa)

Fig. 18 The maximum stress on repaired pipe wrapped with GFRP and CFRP

Based on Fig. 18, it is seen that the CFRP wrapper withstands and exerts lower stress upon various pressure loading compared to the GFRP Wrapper. This static analysis eventually reaffirms that the CFRP is a better wrapping material compared to GFRP [49]. The FOS was considered again to justify the CFRP as a better wrapping material.

Based on Fig. 19, it is seen that the CFRP wrapper has higher minimum safety factor that could withstand higher pressure with minimum safety factor compared to the 


\section{Minimum factor of safety VS Pressure}

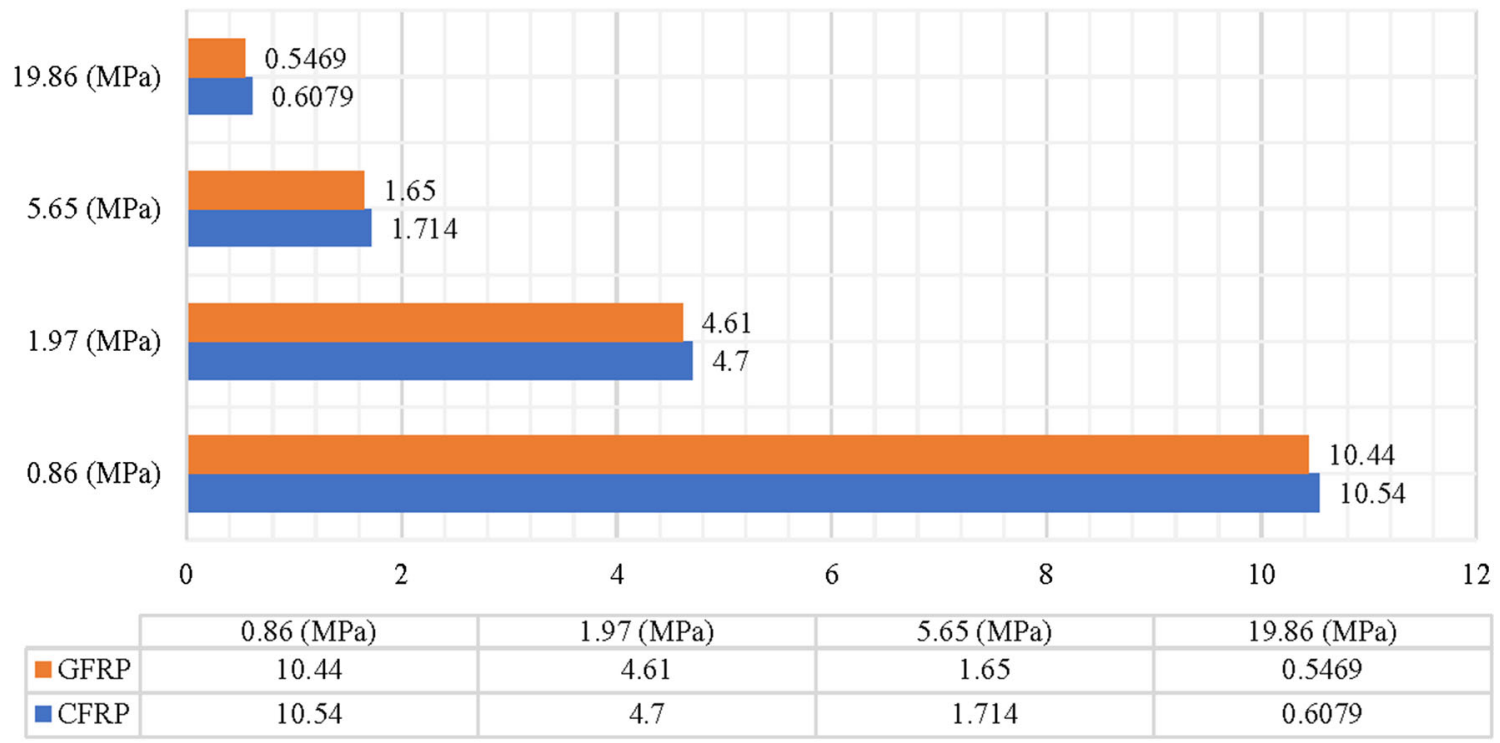

Minimum Factor of Safety

Fig. 19 The minimum safety factor on repaired pipe wrapped with GFRP and CFRP

Table 9 The percentage of stress reduction by CFRP and GFRP wrapper

\begin{tabular}{|c|c|c|c|c|c|c|}
\hline \multirow[b]{2}{*}{$\begin{array}{l}\text { Wrapper } \\
\text { material }\end{array}$} & \multirow[b]{2}{*}{ Pressure } & \multicolumn{2}{|c|}{ Maximum stress (MPa) } & \multirow[b]{2}{*}{$\begin{array}{l}\text { Stress reduction differences } \\
\text { after wrapping (MPa) } \\
\text { (A-B) }\end{array}$} & \multirow[b]{2}{*}{$\begin{array}{l}\text { Percentage of stress } \\
\text { reduction of pipe repair } \\
\frac{A-B}{A} \times 100 \%\end{array}$} & \multirow[b]{2}{*}{$\begin{array}{l}\text { Average }(\%) \text { of stress } \\
\text { reduction of pipe repair }\end{array}$} \\
\hline & & $\begin{array}{l}\text { Unrepaired } \\
\text { defected pipe } \\
\text { (MPa) } \\
\text { (A) }\end{array}$ & $\begin{array}{l}\text { Repaired pipe with } \\
\text { orientation } \\
\text { of } \\
\left(45^{\circ} / 90^{\circ} / 0^{\circ} / 45^{\circ}\right)_{s} \\
\text { (B) }\end{array}$ & & & \\
\hline \multirow[t]{4}{*}{ CFRP } & 0.86 & 363.6 & 24.61 & 338.99 & $93.23 \%$ & $94.10 \%$ \\
\hline & 1.97 & 832.8 & 51.94 & 780.86 & $93.76 \%$ & \\
\hline & 5.65 & 2388 & 141.8 & 2246.2 & $94.06 \%$ & \\
\hline & 19.65 & 8395 & 390.3 & 8004.7 & $95.35 \%$ & \\
\hline \multirow[t]{4}{*}{ GFRP } & 0.86 & 363.6 & 23.46 & 340.14 & $93.55 \%$ & $93.90 \%$ \\
\hline & 1.97 & 832.8 & 53.15 & 779.65 & $93.62 \%$ & \\
\hline & 5.65 & 2388 & 148.5 & 2239.5 & $93.78 \%$ & \\
\hline & 19.65 & 8395 & 448.0 & 7947 & $94.66 \%$ & \\
\hline
\end{tabular}

GFRP Wrapper. Table 9 was tabulated to have numerical comparison in between CFRP and GFRP wrappers with the $\left(45^{\circ} / 90^{\circ} / 0^{\circ} / 45^{\circ}\right)_{s}$ lamination orientation.

Looking at the percentage of the maximum stress reduction of pipe wrapper, CFRP possess higher percentage of stress reduction compared to GFRP. Comparing before repair and after repair of the pipe, on an average about $94.10 \%$ stress was reduced at the defected region by the CFRP wrapper. This average percentage of stress reduction was $0.2 \%$ higher than the GFRP wrapper which possess $93.90 \%$. Although the GFRP reduce the maximum stress by $93.55 \%$ when minimum test pressure was set to be at $0.86 \mathrm{MPa}$, but it possessed lower percentage of maximum stress reduction than the other pressures compared to the CFRP. Indeed, for the pressure $1.97 \mathrm{MPa}$, this CFRP orientation was able to reduce the stress to $93.74 \%$ and $94.02 \%$ for the maximum test pressure of 5.65 MPa compared to unrepaired pipe structure. Even this wrapper was also able to reduce the theoretical maximum test pressure up to $95.20 \%$. This shows that CFRP is a better material to be used as the wrapper compared to GFRP. 
Flow Simulation/CFD Analysis on CFRP Wrapping Structure

The CFD analysis was fully done using the SOLIDWORK Flow Simulation. The aim of this analysis is to make sure that the fluid flow in the pipe is restored and undisrupted after the CFRP wrapper was installed. This will reaffirm the effectiveness of the wrapper on maintaining the pipe's structural integrity [50]. Whenever the inlet velocity and the outlet velocity were set to $10 \mathrm{~m} / \mathrm{s}$ which is the maximum fluid velocity, the internal pressure was loaded as per Fig. 20. These boundary conditions were set at first, before running the simulation. Right after the conditions were loaded up, the flow in a pipe was evaluated.

For this study, the cut plots, surface plots, and few flow trajectories were used to identify the flow study in the pipe. As mentioned earlier, the lamination orientation of the CFRP Wrapper that was used particularly for this analysis is the $\left(45^{\circ} / 90^{\circ} / 0^{\circ} / 45^{\circ}\right)_{s}$ as it was evaluated as the most effective lamination orientation among the other orientations. Upon loading the fluid with various parameters, the pipe structure was enclosed with lids to differentiate the solid and fluid region. At this point, the static pressure was used instead of environmental or total pressure. The total pressure indicates the sum of all the pressure exerted toward the whole system while the environmental pressure refers only to surrounding pressure. Since this analysis only involves fluid pressure, therefore only the static pressure was chosen [40]. Cut plots were basically used to analyze the properties from a section view. This feature eventually allowed to analyze a cross sectioned region and was able to plot the maximum and minimum parameters plot. It had also given an overall idea of the properties like pressure, fluid velocity, and temperature flow along a pipe. Figure 21 illustrates the cut plot normal to front plane of the pipe.

As per the cut plot in Fig. 21a, it shows the maximum pressure was $160.3 \mathrm{kPa}$, and the minimum pressure was $101.309 \mathrm{kPa}$ at this region. Both the maximum and minimum pressures were seen to be at the edge of the openings, and it proves that there were no any leakages at the defected region after CFRP was wrapped. This was because from the cut plot of fluid pressure, the pressure drop was constant along the pipe. By referring to the color codes, there were not any indications that shows there were surge of pressure that possess higher stress at the defected region after the repair. Referring to the temperature cut plot, it was seen that the temperature increases along the length from edge to edge. It could be related to the pressure where when the pressure decrease it will eventually cause an increase in temperature. This situation could be related to Gay Loussac Law which gives $\frac{\text { Pressure } 1}{\text { Temperature1 }}=\frac{\text { Pressure } 1}{\text { Temperature2 }}[51]$. It indicates that the pressure and the temperature are inversely proportional to each other. Moreover, by referring to the velocity cut plot profile it was very clear to see that the velocity at the defected region was fully developed, and there was no sign of turbulence throughout the velocity profile [52].

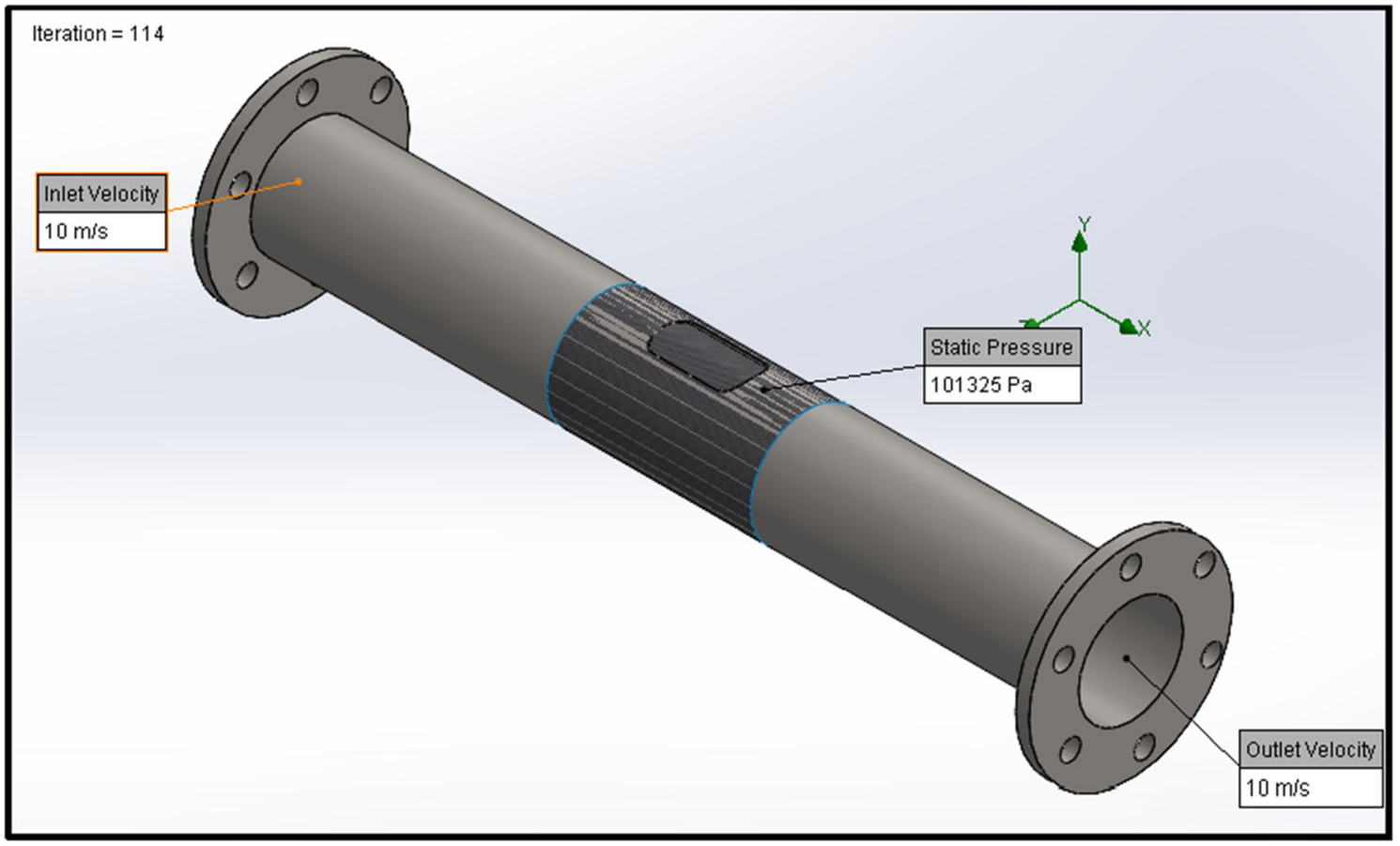

Fig. 20 The boundary conditions on CFRP wrapped pipe 

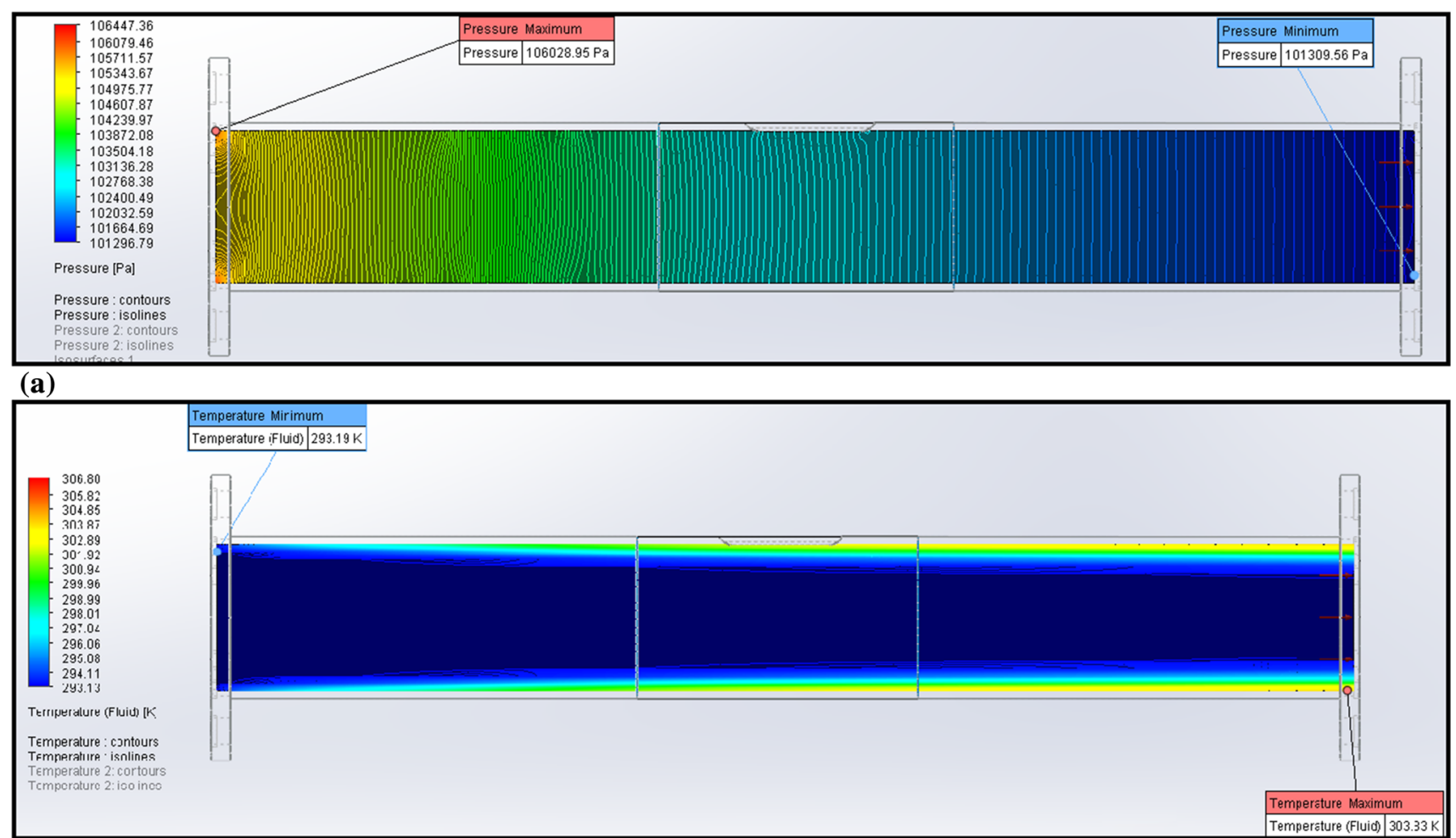

(b)

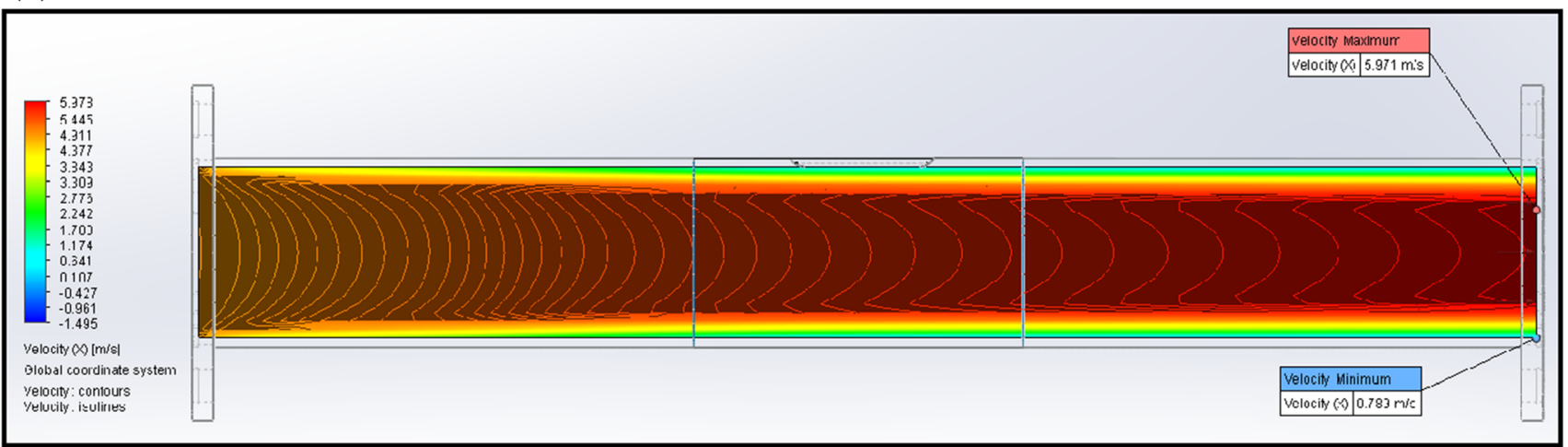

(c)

Fig. 21 The cut plot of the pipe: (a) fluid pressure, (b) fluid temperature, (c) fluid velocity

The surface plots are another type of analysis that could give a better visual analysis and on properties variances. The internal pressure and the temperature inside the pipe that was transmitted to the pipe wall to outer surface of the pipe will eventually give an idea on the properties that was exposed to the surface. Both the surface plots indicate that there were no any critical stress and the thermal stress exposed by the fluid particularly at the defected region after the repair [53]. The surface plots for the pressure on the defected pipe toward the CFRP Wrapper are illustrated in Fig. 22a, and temperature surface plots in Fig. 22b.

On the other hand, the flow trajectories show the fluid particle flow in the pipe. The flow trajectories provide a better visual on the fluid flow in the defected region [54].
Fig. 23 is the right visual that justifies the usage of flow trajectories. Figure 23a and $\mathrm{b}$ distinguish the differences in between the CFRP Wrapped Sealed Defected Pipe and a CFRP Wrapped Unsealed Defected Pipe.

From the flow trajectories profile, it is obvious to see that the CFRP Wrapped Unsealed Defected Pipe accumulates some fluid particles that disrupts the fluid flow, while the CFRP Wrapped Sealed Defected Pipe was having a smooth flow [32]. Moreover, Fig. 24a is the flow trajectories for pressure while Fig. $24 \mathrm{~b}$ is the flow trajectories for temperature followed by flow trajectories for velocity in Fig. 24c. All the flow trajectories shows that the fluid flow was undisrupted after the repair which indicates that the 
Fig. 22 (a) The pressure surface plots, (b) the temperature surface plots
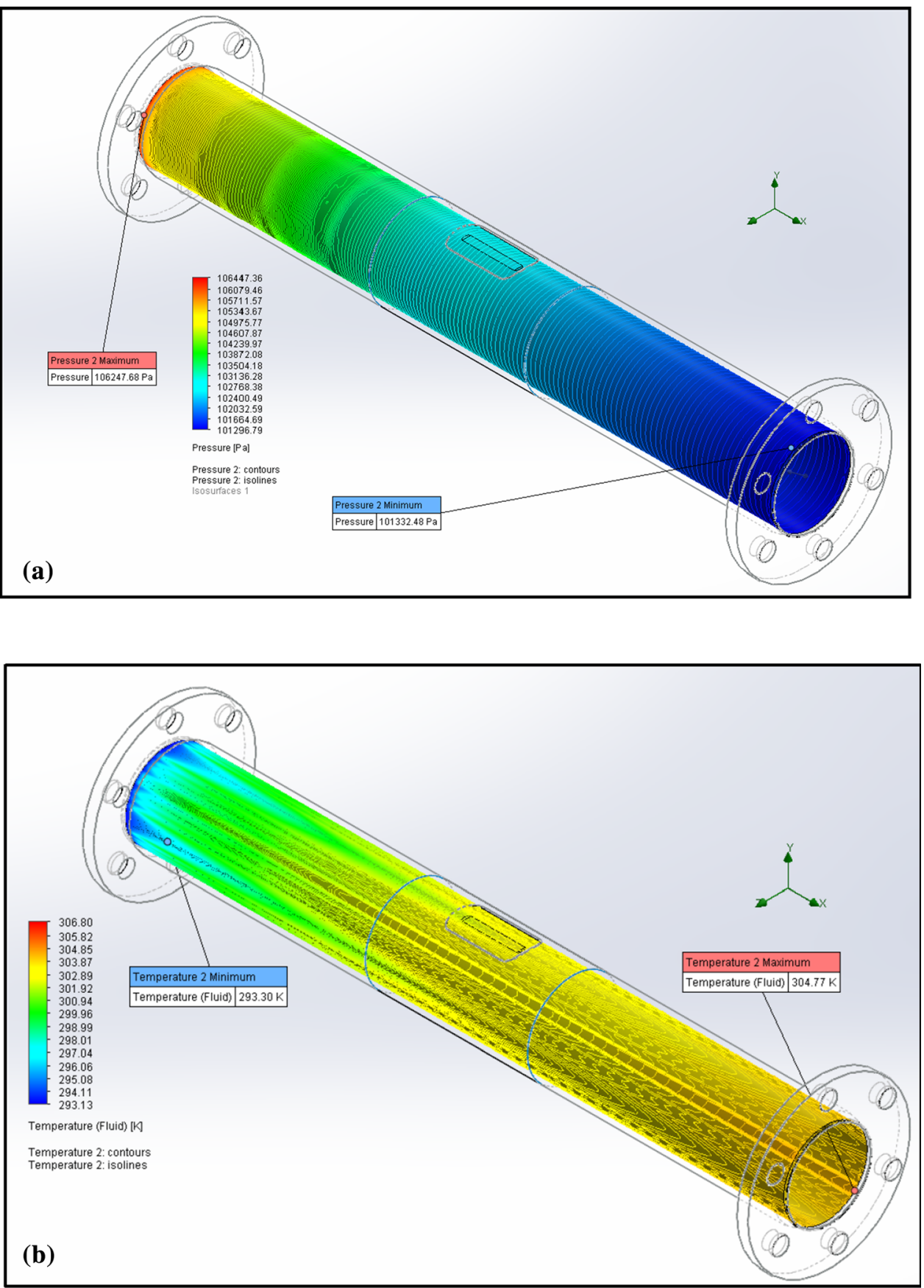

wrapper was effective on maintaining the pipe structural integrity and maintaining the fluid flow.

\section{Conclusion}

Comparing the three types of material GFRP, CFRP, and Nanofiller composite in the first point, theoretically the CFRP have better properties compared with the other two. The research theoretically found that CFRP composite was the most suitable for pipe wrapping material considering the properties are on the optimum conditions. As this whole research was based on simulation only, the outcome from it could give a better justification on considering the CFRP with different lamination orientation as an effective wrapping material in real cases. This research was entirely simulated using SolidWorks software which provides a clear static analysis and flow simulation for CFD studies on evaluating the wrapper's performance on the defected pipe and the fluid flow condition after the CFRP repair. With proper meshing and right material properties application the research managed to entirely simulate and evaluate the 


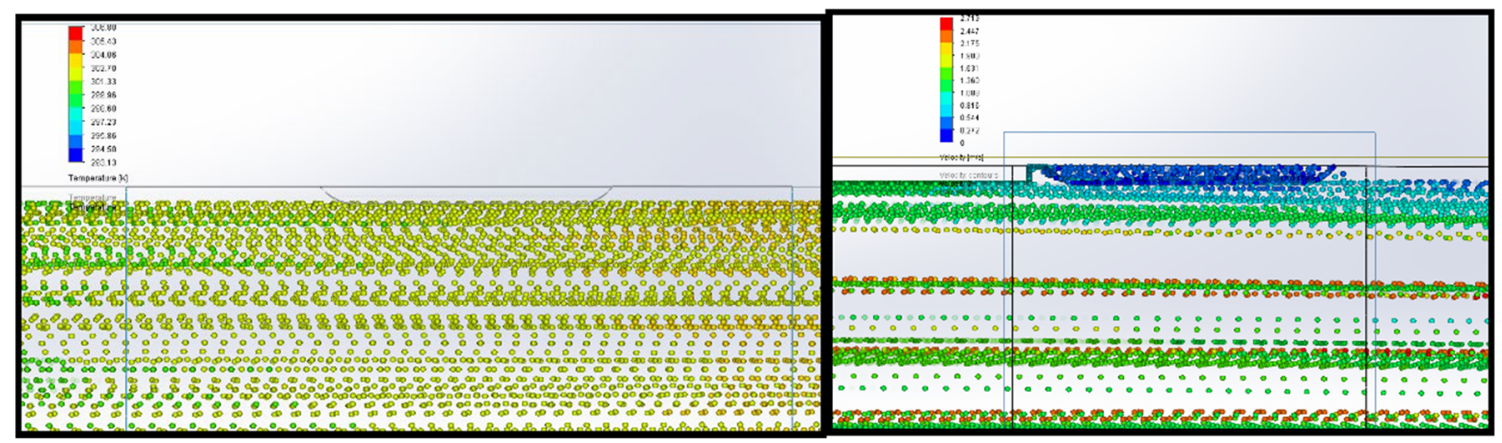

(a)

(b)

Fig. 23 (a) The CFRP wrapped sealed defected pipe, (b) CFRP wrapped unsealed defected pipe

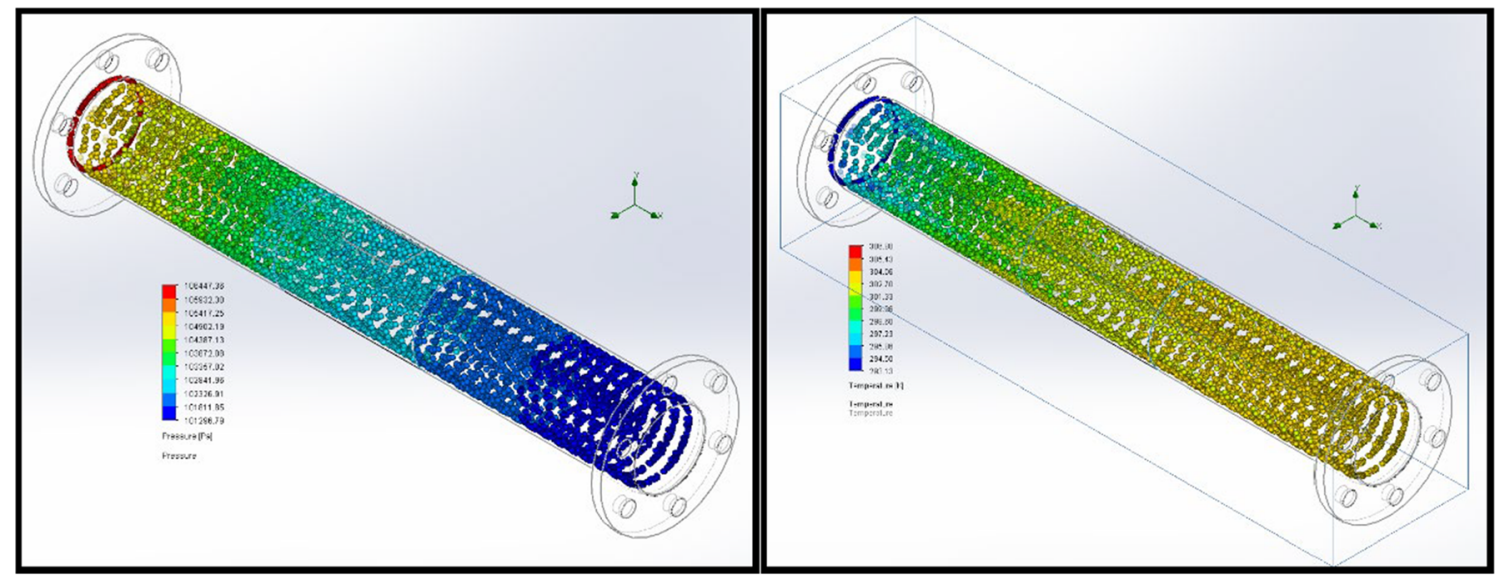

(a)

(b)

Fig. 24 (a) Flow trajectories for pressure, (b) flow trajectories for temperature, (c) flow trajectories for velocity

performance of the CFRP wrapper. Eventually, the research outcome had finally achieve the two objectives that were set for this research. The right lamination and its thickness were finally identified and was evaluated from the SolidWorks software entirely. Those performance were plotted graphically, and the percentage of stress reduction were made. About one unidirectional orientation, 3 symmetric orientations and 4 symmetric orientations were evaluated as a wrapper to repair the defected pipe. Indeed, a sealer was used to cover the defect, and the CFRP was then used to wrap the entire structure. Through the simulation the research gets to distinguish the difference in between the repaired pipe with CFRP lamination and without any repair. Based on all the analysis, the CFRP Lamination Orientation of $\left(45^{\circ} / 90^{\circ} / 0^{\circ} / 45^{\circ}\right)_{8}$ with the layer thickness ranging between 0.16 and $3.76 \mathrm{~mm}$ was identified as a better wrapping structure for 4 types of pressure. Right from 0.86 till 19.65 MPa comparing before repair and after repair of the pipe, on an average about 94.10\% maximum stress was reduced at the defected region by CFRP wrapper. This average percentage of maximum stress reduction was $0.2 \%$ higher than the GFRP wrapper which possess $93.90 \%$. This makes the research to be distinctive because during simulation itself, it was possible to get to know whether the applied wrapper is suitable and optimized could withstand the fluid pressure, and it doesn't create any overload or excessive stress on the repaired pipe. Additionally, the flow simulation analysis in SolidWorks showed that fluid flow was undisrupted after the repair was done, and the wrapped region was resistant to any fluid leakages. It is very important to highlight that this research only provides a preliminary study to justify the lamination orientation and the wrapping material that would be chosen in real cases. This research will be a basis for the real application only. Since it is just an outcome from simulation, an experimental approach is very much advised to be done to further validate the results. For sure, this simulation will save up some cost, effort, and time as the preliminary studies could give the desired lamination orientation for further considerations.

Acknowledgments It has been God's blessing that the completion of this journal could be achieved and completed after facing lots of hurdles during this COVID-19 crisis. We wish to express our sincere gratitude to all the parties, as this journal would not have been the 
same as presented here. We are also indebted to Universiti Tun Hussein Onn Malaysia (UTHM) for providing the facilities for the journal writing and research completion. Our sincere gratitude goes to Research Management Centre of UTHM for fully funding the research and providing adequate support in completing the research under the GPPS Research Grant. Staff at the Faculty of Mechanical and Manufacturing Engineering also deserve special thanks for their assistance during research. Unfortunately, it is not possible to list all of them in this limited space and our personal gratitude to those who had helped us to complete this research directly or indirectly.

\section{References}

1. S. Timashev, A. Bushinskaya, Diagnostics and Reliability of Pipeline Systems, vol 30 (Springer, Switzerland, 2016), p. 1-6

2. NACE International, Basic Corrosion: Student Manual, Version 2.01, (NACE, United States, 2014), pp.1-6

3. E. Orazem, Mark, Underground Pipeline Corrosion: Detection, Analysis and Prevention (Elsevier Woodhead Publishing, Sawston Cambridge, 2014), p. 85-87

4. M. Hadj Meliani, O. Bouledroua, Z.Azari, A. Sorour, N. Merah, ,G. Pluvinage, The inspections, standards and repairing methods for pipeline with composite: a review and case study, in Proceedings of the 17th International Conference on New Trends in Fatigue and Fracture (2018), pp. 147-156

5. K. Farrag, K. Stutenberg, Selection of Pipe Repair Methods. Project Report. Illinois Gas Technology Institute (2013)

6. N. Saeed, H. Ronagh, A. Virk, Composite repair of pipelines, considering the effect of live pressure-analytical and numerical 2 models with respect to ISO/TS 24817 and ASME PCC-2. Compos. Part B Eng. 58, 605-610 (2014)

7. M.M. Watanabe, J.M.L. Reis, H.S. da Costa Mattos, Polymerbased composite repair system for severely corroded circumferential welds in steel pipes. Eng. Failure Anal. 81, 135-144 (2017)

8. C.T. Joen, Y. Park, Q. Wang, A. Sommers, X. Han, A. Jacobi, A review on polymer heat exchangers for HVAC\&R APPLICATIONS. J. Refrig. 32, 763-779 (2009)

9. U. Meier, Carbon fibre-reinforced polymer: modern materials in bridge engineering. Struct. Eng. Int. 2, 7-12 (1992)

10. A.R.K. Boroujeni, Evaluation of FRP (fiberglass reinforced plastic) and RC (rapid cooling) cooling tower. J. Mech. Eng. Res. 3(5), 152-156 (2011)

11. B. Yue Liu, M.S. Swingmann, Carbon fibre reinforced polymer for cable structures. J. Polym. 7, 2078-2099 (2015)

12. W. Grodzki, A. Łukaszewicz, K. Leśniewski, Modelling of UAV's composite structures and prediction of safety factor. Appl. Comput. Sci. 11(3), 67-75 (2015)

13. K. Sandeep, K. Supriya, S. Satbir Singh, CFD analysis with solidworks simulation on FPC with various design parameters. Indian J. Sci. Technol. 9(39), 1-8 (2016)

14. Z. Gurdal, Design and Optimization of Laminated Composite Materials (Wiley, New York, 1999), p. 5-8

15. Y. Liu, B. Swingmann, M. Schlaich, Carbon fibre reinforced polymer for cable structures. J. Polym. 7, 2078-2099 (2015)

16. K. Farrag, K. Stutenberg, Long-term evaluation of the bonding strength of composite repairs, in Proceedings of the 9th International Pipeline Conference (Vol 2, 2012), pp. 611-618

17. D. Plate, Carbon Fibre 101: What do Isotropic, Quasi-Isotropic, and Anisotropic Mean? Retrieved on 25th November 2019 from, https://dragonplate.com/carbon-fiber-101-what-do-isotropicquasi-isotropic-and-anisotropic-mean

18. K. Ghaedi, Z. Ibrahim, A. Javanmardi, M. Jameel, U. Hanif, S.K. Rehman, M. Gordan, Finite element analysis of a strengthened beam deliberating elastically isotropic and orthotropic CFRP material. J. Civ. Eng. Sci. Technol. 9(2), 117-126 (2018)

19. H.M. Rahamani, S.H. Najafi, S. Saffarzadeh-Matin, A. Ashori, Mechanical properties of carbon fiber/epoxy composites: effects of number of plies, fiber contents, and angle-ply layers. Polym. Eng. Sci. 54(11), 733-740 (2014)

20. Y. Liu, B. Zwingmann, M. Sclaich, Carbon fiber reinforced polymer for cable structures-a review. Polymers. 7(10), 20782099 (2015)

21. M. Alberto, Introduction of Fibre-Reinforced Polymers-Polymers and Composites: Concepts Properties and Processes (InTech, Croatia, 2013), p. 8-19

22. G. Qi, D. Qi, Q. Bai, H. Li, B. Wei, N. Ding, X. Shao, Failure analysis on pressure leakage Of FRP. Journal of Fibres and Polymers. 20(3), 595-601 (2019)

23. M.P. Kruijer, L.L. Warnet, R. Akkerman, Analysis of the mechanical properties of a reinforced thermoplastic pipe (RTP). Compos. A Appl. Sci. Manuf. 36(2), 291-300 (2005)

24. G. Aklilu, G. Bright, S. Adali, Temperature effects on failure of rotating beam of hybrid composite. J. Fail. Anal. Prev. 20(5), 1583-1597 (2020)

25. E.S.M.M. Soliman, Static and vibration analysis of CFRP composite mono leaf spring. J. Fail. Anal. Prev. 19, 5-14 (2019)

26. HardHat Engineer, A Complete Guide to Pipe Sizes and Pipe Schedule-Free Pocket Chart, Retrieved on 02 July 2018 from, https://hardhatengineer.com/pipe-class-piping-specificationspipeend/pipe-schedule-chart-nominal-pipe-sizes/

27. H.S. Wass, R.P. Fleming, Sprinkler Hydraulics: A Simplified Method for Calculating Pipe Schedule Systems (Springer International Publishing, Cham, 2020), p. 107-111

28. A. Bhatia, Process Piping-Fundamental, Codes and Standards, (PDH Engineer: Online Continuing Education for Engineers, 2016), pp. 2-52

29. Dassault Systems SolidWorks Education, An Introduction to Flow Analysis Applications with SolidWorks Flow Simulation, Student Guide, Engineering Design and Technology Series, 1-24 (2010)

30. A. Jonukaite, Flow Simulation with SolidWorks, Bachelor Thesis, Arcada University of Applied Science, Finland (2017)

31. O. Ionel, A CFD analysis in solidworks flow simulation for two mixing fluids with different temperatures in nozzles. J. Eng. Stud. Res. 26(1), 41-46 (2020)

32. K. Sing Lim, Behaviour of Repaired Composite Steel Pipeline Using Epoxy Grout as Infill Material. Ph.d Thesis, Universiti Teknologi Malaysia, Malaysia (2017)

33. Los Alamos National Laboratory, LANL Engineering Standards Manual PD342 ASME B31.3 Process Piping Guide Revision 2, (Los Alamos National Laboratory New Mexico, United States, 2009)

34. S.K. Nawandar, Considering Hydrotest Pressure Loading in the Calculation of MAWP of a Pressure Vessel, in Proceedings of the Computer Technology and Bolted Joints; Design and Analysis, 2 (2021), pp. 1-56

35. P.S. Prashob, A.P. Shashikala, T.P. Somasundaran, Determination of orthotropic properties of carbon fiber reinforced polymer by tensile tests and matrix digestion, in International Conference on Composite Materials and Structures-ICCMS (2017), pp. 1-10

36. L. Carolines, Nonlinear-elastic orthotropic material modelling of an epoxy-based polymer for predicting the material behavior of transversely loaded fiber-reinforced composites. J. Compos. Sci. 4, 2-22 (2020)

37. D. Ferras, D.I. Covas, A.J. Schleiss, Stress-strain analysis of a toric pipe for inner pressure loads. J. Fluids Struct. 51, 68-84 (2014)

38. V. Marthini, I.A.A. Alhelali, M. Mohd Afendi, W.M.S. Majid, W. Sulong, Effect of quenching on the mechanical properties of 
carbon steel for hammer mill. J. Phys. Conf. Ser. 2051, 1-7 (2021)

39. M. Eesa, CFD Studies of Complex Fluid Flow in Pipes. PhD Thesis, The University of Birmingham, Birmingham (2009)

40. O. Vestrum, M. Kristoffersen, A. Mario, P. Loria, H. Ilstad, M. Langseth, T. Borvik, Quasi-static and dynamic indentation of offshore pipelines with and without multi-layer polymeric coating. J. Mar. Struct. 62, 60-76 (2018)

41. S.M. Fayyad, Analysis and simulation of contact stresses of convex punch. ISOR J. Eng. 3, 59-67 (2013)

42. J.M. Duell, Characterization and FEA of A Carbon Composite Overwrap Repair System. Master Thesis, The University of Tulsa, USA (2004)

43. P. Sharma, M. Tiwari, K. Sharma, Design and analysis of a process plant piping system. Int. J. Curr. Eng. Technol. Special Issue. 3, 31-39 (2014)

44. R. Ashari, A. Eslami, M. Shamanian, Corrosion and electrochemical conditions of pipeline steel under tape coating disbondments: effect of disbondment gap size and morphology. J. Pipeline Syst. Eng. Pract. 11(1), 1-9 (2020)

45. P.V. Burkov, S.P. Burkova, S.A. Knaub, Stress and strain state analysis of defective pipeline portion. IOP Conf. Ser. Mater. Sci. Eng. 91, 12-55 (2015)

46. T. Poutanen, T. Lansivaara, S. Pursiainen, J. Makinen, O. Asp, Calculation of safety factors of the eurocodes. J. Appl. Sci. 11(1), 208 (2021)

47. M. Meriem-Benziane, S.A. Abdul-Wahab, H. Zahloul, B. Babaziane, M. Hadj-Meliani, G. Pluvinage, Finite element analysis of the integrity of an API X65 pipeline with a longitudinal crack repaired with single- and double-bonded composites. Compos. B Eng. 77, 431-439 (2015)

48. D. Vaiciulis, A. Brazenas, Determination of stress strain state in pipe subjected to internal pressure at plane strain condition, under elasto plastic loading. Mechanika. 17(4), 346-351 (2011)

49. C. Elanchezhian, B. Vijaya Ramnath, J. Hemalatha, Mechanical behavior of glass and carbon fibre reinforced composites at varying strain rates and temperature. Procedia Mater. Sci. 6, 1405-1418 (2014)

50. N. Dwivedi, V. Kumar, Burst pressure prediction of pressure vessel using FEA. Int. J. Eng. Res. Technol. 1(7), 1-6 (2012)

51. N. Kilmer, J.D. Krehbiel, Improved gay-lussac experiment considering added volumes. Phys. Teacher. 57, 21-25 (2019)

52. N. Makwashi, K. Sarkodie, S. Akubo, D. Zhao, P. Diaz, Investigation of the severity of wax deposition in bend pipes under subcooled pipelines conditions, in 81st EAGE Conference and
Exhibition; Society of Petroleum Engineers, SPE-195559-MS (2019), pp. 1-23

53. E. Bellos, C. Tzivanidis, K.A. Antonopoulos, Thermal performance of a direct-flow coaxial evacuated tube with solidworks flow simulation, in 6th International Conference on Experiments, Process, System Modeling, Simulation, Optimization at Athens Greece (2015), pp. 1-8

54. J.E. Matsson, An Introduction to SolidWorks Flow Simulation 2021 (SDC Publications, New York, 2021), p. 38-43

55. M. Al-Amin, W. Zhou, Evaluating the system reliability of corroding pipelines based on inspection data. Struct. Infrastruct. Eng. 10(9), 1161-1175 (2013)

56. S. Timashev, A. Bushinskaya, Methods of assessing integrity of pipeline systems with different types of defects Diagnostics and reliability of pipeline systems. Topi Saf Risk Reliab Qual. 30, 943 (2016)

57. A. Cosham, P. Hopkins, K.A. Macdonald, Best practice for the assessment of defects in pipelines-corrosion. Eng. Fail. Anal. 14, 1245-1265 (2007)

58. K. Sing Lim, S.A.A. Azraai, N. Yahaya, N. Noor, L. Zardasti, J.H.J. Kim, Behaviour of steel pipelines with composite repairs analyzed using experimental and numerical approaches. J. Thin Wall. Struct. 139, 321-333 (2019)

59. Melander, Fibre Reinforced Polymers for Rehabilitation of Action Research and Case Study, Master Thesis, Chalmers University of Technology (2016)

60. A.M. Tajul Arifin, S. Abdullah, R. Zulkifli, D.A. Wahab, A study on characteristic of polymer matrix composites using experimental and statistical approach. Appl. Mech. Mater. 368-370, 683-686 (2013)

61. L.B. Godefroid, B.M. Sena, V.B.T. Filho, Evaluation of microstructure and mechanical properties of seamless steel pipes API $5 \mathrm{~L}$ type obtained by different processes of heat treatments. Mater. Res. 20, 1-9 (2017)

62. S. Nasrazadani, M.S.T. Alpona, C. Aurva, Failure analysis of API 5L (grade B) oil field separator flowline pipe. J. Failure Anal. Prevent. 18(4), 721-726 (2018)

63. A.U. Winistoefer, Developemnt of Non-Laminated Advanced Composite Straps for Civil Engineering Applications. Ph.D. Thesis, The University of Warwick (1999)

Publisher's Note Springer Nature remains neutral with regard to jurisdictional claims in published maps and institutional affiliations. 